\title{
Pilot Scale Recovery of Phosphorus as Calcium Phosphate from Nitrified UASB effluent of a Potato Processor and Subsequent Reuse in the Wet Process for Phosphoric Acid Production
}

\author{
Boudewijn Meesschaert ${ }^{\mathrm{a},{ }^{*}}$, Annick Monballiu $^{\mathrm{a}}$, Karel Ghyselbrecht ${ }^{\mathrm{a}}$, Cédric Van Goethem ${ }^{\mathrm{b}}$, Hubert \\ Halleux ${ }^{c}$ and Luc Pinoy ${ }^{d}$ \\ a Department of Microbial and Molecular Systems, Faculty of Engineering Technology, KU Leuven \\ Bruges Campus, Spoorwegstraat 12, B-8200 Brugge, Belgium \\ b Department of Microbial and Molecular Systems, Faculty of Bioscience Engineering, KU Leuven, \\ Celestijnenlaan 200F, B-3000 Leuven \\ c Prayon nv, Gansbroekstraat 31, B-2870 Ruisbroek, Belgium \\ ${ }^{\mathrm{d}}$ Department of Chemical Engineering, Faculty of Engineering Technology, KU Leuven Ghent \\ Technology Campus, Gebroeders De Smetstraat 1, B-9000 Gent, Belgium
}

* Corresponding author: boudewijn.meesschaert@kuleuven.be

\begin{abstract}
In the frame of the sustainable use of phosphorus, a pilot scale experiment ran for more than one year on the effluent of an upstream anaerobic sludge blanket reactor (UASB) of a potato processor to recover phosphorus as calcium phosphate. Calcium phosphate may be mixed with phosphorous ore and as such used in phosphoric acid production. The effluent was first nitrified and - at neutral pH adding calcium ions from calcium chloride in a ratio of about 4 or 8 relatives to phosphate-P, resulted in $80 \%$ respectively $90 \%$ phosphorous recovery as calcium phosphate. In the P-reactor a brown colour developed, a colour that remained in the precipitates. After ultrafiltration of the nitrified UASB effluent the recovered precipitates still contained organic material. The phosphorous content of the recovered precipitates expressed as $\mathrm{P}_{2} \mathrm{O}_{5}$, was 35 to $40 \mathrm{~m} \%$; the precipitates also contained 4 to $8 \mathrm{~m} \%$ calcium carbonate. Except for the criteria for organic material (best $1.67 \mathrm{~m} \%$ TOC vs 0.40 $\mathrm{m} \%)$ ) and magnesium ( $0.56 \mathrm{~m} \%$ as $\mathrm{MgO}$ vs $0.11 \mathrm{~m} \%)$, the precipitates fulfilled all the criteria for phosphorous ore. In a two-step calcination process milled coloured precipitate was converted over a light grey $\left(600^{\circ} \mathrm{C}\right)$ to a pure white product $\left(900 \mathrm{C}^{\circ}\right)$. This calcination enhanced the crystallinity of the precipitates. A mixture of non-calcinated precipitates (total $30 \mathrm{~kg}$ ) was used for phosphoric acid production. Both the acid and the isolated calcium sulphate were coloured but fulfilled most other chemical criteria. Not the magnesium contamination but either the contamination with organic material appeared to be a problem.
\end{abstract}

Keywords: Pilot scale, nitrification, phosphorus reclamation, calcium phosphate, hydroxyapatite 


\section{Introduction}

Phosphorus is an essential element for all living organism. Plants are at the start of the food chain and need fertilizers, including phosphorus for good development, especially within the frame of intensive agriculture. The increasing world population, the worldwide increased consumption of meat and dairy products and the increased use of biofuels in the frame of the reduction of carbon dioxide emissions from fossil fuels, causes a global expansion of agricultural activities and the use of fertilizers [1]. Classic compound fertilizers contain nitrogen, phosphorus and potassium (N-P-K fertilizers). Nitrogen from the air is converted in ammoniacal nitrogen in the Haber - Bosch process. And, although this process consumes lots of energy and has a high carbon footprint, the stock of nitrogen is virtually unlimited because it makes up $79 \%$ of the air. Phosphorus and potassium from the other side are derived from natural occurring sediments that are limited in quantity and quality. Especially for phosphorus doubts arise about the availability in the future, and although difficult to predict, it may well be that the stock of easily accessible phosphorous ore of enough quality is used up within about 100 years [1,2]. In this context the EU declared phosphorous ore a critical compound [3].

In the past, inorganic phosphorous fertilizers as well as manure, as source of phosphorus and nitrogen, have been used extensively in several parts of the Western world and have caused a supersaturation of the soil of farmland with phosphorus. Direct and postponed run off from the land to surface waters have largely contributed to the phenomenon of eutrophication of several water bodies. In this context strict laws have been implemented on the use of phosphorous fertilizers and on the phosphorous content of the effluent of wastewater treatment facilities that discharge their effluent on surface waters. Depending on the volumes discharged, the discharge limit for total phosphorus is $1-2 \mathrm{mg}$ total P.L-1. To realize this strict limit in most cases iron and/or aluminium salts are used to remove the phosphate together with the sludge at the end of the wastewater treatment. An alternative is to activate enhanced biological phosphate removal (EBPR) by alternating aerobic and anoxic phases, which causes the sludge to accumulate polyphosphates. Both methods have in common that the phosphorus accumulates in the sludge. Germany issued a law that stipulates that phosphorus must be recovered from the sludge of wastewater treatment facilities that are built for more than 50000 population equivalents [4].

When the phosphate concentration in the wastewater is high enough, it can be directly recovered from the water; $50 \mathrm{mg} \cdot \mathrm{L}^{-1}$ is put forward as a minimum [5]. Especially the wastewaters of some food industries, such as potato processors contain enough phosphate and are eligible for this [6]. In practice the recovery of phosphate is performed after the anaerobic phase of the treatment. This anaerobic step is a mineralization step and produces an effluent with free ammonium $\left(\mathrm{NH}_{4}{ }^{+}\right)$and free phosphate $\left(\mathrm{HPO}_{4}{ }^{2}\right)$. The challenge is then to convert this soluble phosphate to an insoluble form.

Nature offers a few examples of insoluble phosphate salts. Struvite $\left(\mathrm{NH}_{4} \mathrm{MgPO}_{4} \cdot 6 \mathrm{H}_{2} \mathrm{O}\right)$ is known for a long time as a kind of kidney stones and a technology for the recovery of phosphate as struvite was perfected at different places around the world $[1,6]$. Also calcium phosphate $\left(\mathrm{Ca}_{3}\left(\mathrm{PO}_{4}\right)_{2}\right)$ and crystalline equivalents such as hydroxyapatite ( $\left.\left.\mathrm{HAP} ; \mathrm{Ca}_{5}\left(\mathrm{PO}_{4}\right)_{3} \mathrm{OH}\right)\right)$ are naturally occurring rather insoluble phosphate salts that occur e.g. in bone, dentine, email and teeth calculus, and the recovery of phosphate as calcium phosphate can be an alternative to the struvite technology. Calcium phosphate can also be used as fertilizer and especially its recovery from livestock wastewater has been proposed $[7,8]$. Calcium phosphate has also the advantage over struvite that it can be mixed with phosphorous ore, which has about the same chemical composition [9], and directly used in the wet process for phosphoric acid production; see reaction (1) for a simplified version for the chemistry involved. 


$$
\mathrm{Ca}_{3}\left(\mathrm{PO}_{4}\right)_{2}+3 \mathrm{H}_{2} \mathrm{SO}_{4}+6 \mathrm{H}_{2} \mathrm{O} \rightarrow 2 \mathrm{H}_{3} \mathrm{PO}_{4}+3 \mathrm{CaSO}_{4} \cdot 2 \mathrm{H} 2 \mathrm{O}
$$

The requirements set by the phosphorous industry for recovered calcium phosphate are the same as those for phosphorous ore. These requirements should not just guarantee the quality of the produced phosphoric acid, but also of the by-product calcium sulphate (gypsum; $\mathrm{CaSO}_{4} \cdot 2 \mathrm{H}_{2} \mathrm{O}$ ), which is a useful chemical substance to produce plaster and plasterboards. For a $\mathrm{P}_{2} \mathrm{O}_{5}$ content of $15 \mathrm{~m} \%$ on dry matter the most important requirements are: chloride (max. $\left.150 \mathrm{mg} \cdot \mathrm{kg}^{-1}\right), \mathrm{Cd}\left(\max .1 \mathrm{mg} \cdot \mathrm{kg}^{-1}\right)$, As total (max $1 \mathrm{mg} \mathrm{kg}^{-1}$ ), potassium (0.15 m\% ; expressed as $\mathrm{K}_{2} \mathrm{O}$ ), magnesium (0.04 m\% as $\mathrm{MgO}$ ), $\mathrm{SiO}$ (as low as possible) and total organic carbon $(0.15 \mathrm{~m} \%)$.

The precipitation of calcium phosphate for phosphate recovery is already under study for a long time and Morse et al. [ 10] included the method in their overview of 1997. Very interesting is the DHV Crystalactor ${ }^{\circledast}$ technology which is a modification of a water softening method [11]. This process is based on the crystallisation of calcium phosphate on a seed material, typically sand, in a fluidized bed reactor. Alkaline conditions are maintained by the addition of either caustic soda or lime. The fact that the water to be treated first must be acidified to $\mathrm{pH} 3$ to expel carbonates as carbon dioxide before it enters the fluidised bed makes this method however highly unsustainable. A variety of other seed crystal materials such as calcite, apatite, cow bone, tobermorite and xonotlite have already been reported [12]. Calcite, a form of calcium carbonate, is probably not suited as seed crystal when the recovered phosphate is intended for phosphoric acid production since this will lead to extra consumption of sulphuric acid and foaming due to the of formation carbon dioxide gas [13]; see reaction (2)

$$
\mathrm{CaCO}_{3}+\mathrm{H}_{2} \mathrm{SO}_{4}+2 \mathrm{H}_{2} \mathrm{O} \rightarrow \mathrm{CaSO}_{4} \cdot 2 \mathrm{H}_{2} \mathrm{O}+\mathrm{H}_{2} \mathrm{CO}_{3}\left(\rightarrow \mathrm{H}_{2} \mathrm{O}+\mathrm{CO}_{2}\right)
$$

Carbonate $\left(\mathrm{CO}_{3}{ }^{2-}\right)$ has also a negative effect on calcium phosphate precipitation [14 ]. At pH 8.00 the precipitation is greatly retarded and at higher $\mathrm{pH}$ values calcium carbonate contaminates the recovered calcium phosphate. The effect of carbonate is attributed to the formation of ion pairs between carbonate and calcium reducing the concentration of free calcium ions [14]. Since the predominating form of dissolved inorganic carbon at $\mathrm{pH} 8.00$ is bicarbonate $\left(\mathrm{HCO}_{3}{ }^{-}\right)$the latter has been suggested as a direct inhibitor of calcium phosphate formation [15]. This effect explains why in the DHV Crystalactor ${ }^{\circledR}$ a preceding acidification and degasification is necessary.

Teeth calculus (tartare) is made from calcium phosphate and HAP and the chemistry behind this tartare formation inspired Monballiu et. al [15] to develop a method for phosphate recovery as calcium phosphate. A nitrification of the UASB effluent was introduced to remove most of bicarbonate alkalinity or dissolved inorganic carbon (DIC). See reactions (3) to (5). In this mechanism, the aeration, which is necessary for the nitrification (reaction 3 ) is also responsible for blowing out carbon dioxide; reaction (4). The net effect is that calcium ions which previously were in ion pairs with carbonate/bicarbonate become available for phosphate precipitation [14].

$$
\begin{array}{lll} 
& \mathrm{NH}_{4}^{+}+2 \mathrm{O}_{2} \rightarrow \mathrm{NO}_{3}^{-}+\mathrm{H}_{2} \mathrm{O}+2 \mathrm{H}^{+} \\
\text {SUM: } & \frac{2 \mathrm{HCO}_{3}^{-}+2 \mathrm{H}^{+} \rightarrow 2 \mathrm{H}_{2} \mathrm{CO}_{3} \rightarrow 2 \mathrm{H}_{2} \mathrm{O}+2 \mathrm{CO}_{2} \uparrow}{2 \mathrm{NH}_{4}^{+}+4 \mathrm{O}_{2}+4 \mathrm{HCO}_{3}^{-} \rightarrow 2 \mathrm{NO}_{3}^{-}+6 \mathrm{H}_{2} \mathrm{O}+4 \mathrm{CO}_{2} \uparrow} \\
& \mathrm{HPO}_{4}^{2-}+\mathrm{H}_{2} \mathrm{PO}_{4}^{-}+3 \mathrm{Ca}^{2+} \rightarrow \mathrm{Ca}_{3}\left(\mathrm{PO}_{4}\right)_{2}+3 \mathrm{H}^{+} \\
\text {SUM: } & \frac{3 \mathrm{H}^{+}+3 \mathrm{HCO}_{3}^{-} \rightarrow 3 \mathrm{H}_{2} \mathrm{CO}_{3}\left(\rightarrow 3 \mathrm{CO}_{2}+3 \mathrm{H}_{2} \mathrm{O}\right)}{\mathrm{HPO}_{4}^{2-}+\mathrm{H}_{2} \mathrm{PO}_{4}^{-}+3 \mathrm{Ca}^{2+}+3 \mathrm{HCO}_{3}^{-} \rightarrow 3 \mathrm{H}_{2} \mathrm{O}+3 \mathrm{CO}_{2}+\mathrm{Ca}_{3}\left(\mathrm{PO}_{4}\right)_{2}}
\end{array}
$$

By removing most of the DIC, the precipitation of phosphate as calcium phosphate becomes thus possible at neutral $\mathrm{pH}$ and without the addition of caustic soda or lime; reaction (6). It is the endogenous DIC (bicarbonate; $\mathrm{HCO}_{3}^{-}$) that not only consumes the protons that are exempt during the 
nitrification (reaction 4), but also those that arise during the precipitation of calcium phosphate; reaction (7) [16]. Reaction (8) describes calcium phosphate precipitation in combination with bicarbonate consumption. This reaction fits within current known aspects of phosphate and bicarbonate chemistry.

$$
\begin{aligned}
& 2 \mathrm{Ca}_{3}\left(\mathrm{PO}_{4}\right)_{2}+6 \mathrm{H}_{2} \mathrm{O}+6 \mathrm{CO}_{2} \rightarrow 2 \mathrm{CaHPO}_{4}{ }^{2-}+\mathrm{Ca}\left(\mathrm{H}_{2} \mathrm{PO}_{4}^{-}\right)_{2}+3 \mathrm{Ca}\left(\mathrm{HCO}_{3}^{-}\right)_{2} \\
& 2 \mathrm{Ca}_{3}\left(\mathrm{PO}_{4}\right)_{2}+12 \mathrm{H}_{2} \mathrm{O}+12 \mathrm{CO}_{2} \rightarrow 4 \mathrm{H}_{3} \mathrm{PO}_{4}+6 \mathrm{Ca}\left(\mathrm{HCO}_{3}^{-}\right)_{2} \\
& \mathrm{Ca}_{10}\left(\mathrm{PO}_{4}\right)_{6}(\mathrm{OH})_{2}+18 \mathrm{H}_{2} \mathrm{O}+20 \mathrm{CO}_{2} \rightarrow 6 \mathrm{H}_{3} \mathrm{PO}_{4}+10 \mathrm{Ca}\left(\mathrm{HCO}_{3}\right)_{2}
\end{aligned}
$$

Reaction (9) is the net reverse of reaction (8) and may evolve to reaction (10) depending on $\mathrm{pH}$ and the excess of carbon dioxide. Both reaction (9) and (10) indicate that dissolving of calcium phosphate is possible by adding carbon dioxide. Toyama [17] investigated the possibility of dissolving calcium phosphate salts from sewage sludge ash by the carbon dioxide blowing method and postulated reaction (11) for the solubilisation of dimeric HAP in this acidic condition. Also, the ExtraPhos ${ }^{\circledR}$ process of Budenheim uses carbon dioxide to solubilize phosphate from sludge [18].

Vanotti and co-workers $[7,8]$ used a nitrification of livestock wastewater but still used alkali for the precipitation of phosphate as calcium phosphate. The procedure developed by Monballiu et al. [16, 19] focuses however on the precipitation of phosphate at neutral $\mathrm{pH}$, since increasing the $\mathrm{pH}$ above neutral $\mathrm{pH}$ will inevitably lead to coprecipitation of excess magnesium phosphate $[19,20]$ a contamination which is irreconcilable with the potential use of recovered calcium phosphate in the wet process for phosphoric acid production, since contamination with magnesium is not allowed. Magnesium increases the viscosity of the reaction medium and decreases the kinetics and crystalline growth of gypsum; see reaction (1). It also contributes to the formation of insoluble complex mineral phases, causing fouling problems and considerable losses of phosphorus [21].

The precipitation of phosphate necessarily involves the release of protons; reaction (6). In electrochemical induced calcium phosphate precipitation these protons are neutralized by hydroxide ions formed by cathodic reduction of water at a titanium electrode [22]. This results in a local pH increase that causes calcium and magnesium phosphate to precipitate. In view of the idea to produce calcium phosphate that is suitable for use in phosphoric acid production, this method lacks selectivity as also calcite (calcium carbonate) and brushite (magnesium hydroxide) precipitate even in conditions that are optimized for calcium phosphate precipitation [23].

Phosphate recovered as impure calcium phosphate with the idea to use it as fertilizer will probably suffer from the same marketing problems as struvite. However, it appears that precipitation of calcium phosphate at neutral $\mathrm{pH}$ is a good approach to recover it more or less free from contaminants $[16,19]$. This opens the way to a much broader use of the recovered phosphate as e.g. in phosphoric acid production. Monballiu et al. used their approach for the precipitation of phosphate as calcium phosphate at neutral pH after nitrification in batch tests [19] as well as in continuously fed CSTR's [16] on lab scale. Monballiu et al. also concluded that an extra denitrification did not result in a better recovery of phosphate [20] since the denitrification caused both the $\mathrm{pH}$ and the DIC to increase. The $\mathrm{pH}$ increase led to an increase in contamination with magnesium phosphate and the increase in DIC led to an increase in contamination with calcium carbonate. In addition, the fact that the $\mathrm{pH}$ increases during denitrification resulted in $25-40 \%$ loss of phosphate in the reactor [20].

This approach for phosphate recovery which is implemented between the nitrification and denitrification has as extra advantage that struvite cannot precipitate as ammonium is no more available. Nitrification is thus also a pre-treatment that contributes to the goal of recovering magnesium free calcium phosphate. Furthermore, recent results show that a high ammonium over P- 
ratio (N/P ratio) negatively influences calcium phosphate precipitation: the higher the N/P ratio the lower is the growth rate of the crystals of either dicalcium phosphate dihydrate (DCPD; $\mathrm{pH}=4.5$ 5.7) and HAP ( $\mathrm{pH}>6.3)$ [24]. Removing ammonium should thus also improve the crystallization process.

In this contribution a pilot scale experiment that lasted for more than one year is described in which phosphate is recovered as calcium phosphate from wastewater of a potato processor, more precisely from the nitrified UASB effluent. The effect of varying molar $\mathrm{Ca} / \mathrm{P}$ ratios, of different types of filtration, of the continuity of feeding the P-reactor and of the continuity of mixing or aerating the Preactor is investigated on the yield of the recovery, the purity and the crystallinity of the precipitates. It was investigated how the precipitates can be upgraded and $30 \mathrm{~kg}$ precipitate was used in a pilot test for phosphoric acid production.

\section{Materials and Methods}

a. Origin of the wastewater and nitrification

UASB effluent of the new production facility of Agristo, a potato processor, at Wielsbeke (Belgium) was nitrified on site. The effluent was first subjected to a pre-settlement (Fig. 1) in two interconnected IBC's (international bulk containers) of $1 \mathrm{~m}^{3}$. The flow rate to the nitrification reactor was $40-60 \mathrm{I}^{-\mathrm{h}^{-1}}$ (HRT in IBC $2=16-24$ hours). The nitrification reactor was $1.5 \mathrm{~m}^{3}$ and the HRT of the UASB effluent was thus about $24-36$ hours. The reactor was inoculated with $750 \mathrm{~L}$ sludge from the wastewater treatment of the company and the reactor was aerated with compressed air. The flow rate of the influent to the reactor and of the air were adjusted to each other so that just full nitrification occurred. The nitrification was monitored on the spot with quick tests for the detection of nitrate (Quantofix, MN) and ammonium (MQuant, Merck). The reactor was equipped with a $300 \mathrm{~L}$ decanter for sludge settlement and the recycle to the reactor had a flow rate of $200 \mathrm{~L}^{-\mathrm{h}^{-1}}$. The decanter spilled over in a third IBC for further settlement of the sludge.

b. Ultrafiltration, UV C treatment and gradual improvement of the set up

Initially (Phase 1 - 3), the nitrified effluent in the third IBC spilled over to a fourth that was used as reactor for phosphate recovery (short-cut in Fig. 1 to IBC 5, the P-reactor). A commercial calcium chloride solution was added continuously to the P-reactor ( $33 \mathrm{~m} \% \mathrm{CaCl}_{2}$; varying flow rates; Nedmag Industries, Veendam, The Netherlands) and the $\mathrm{P}$ reactor was either moderately mixed with a mechanical stirrer (Phase 1) or vigorously mixed continuously with a submersible pump (Phase 2). A further adjustment (Phase 3) was to circulate the nitrified effluent over a $25 \mu \mathrm{m}$ candle filter to reduce the suspended solids. In this experiment the P-reactor was mixed with the submersible pump every 2.5 hours for 5 minutes. In all phases the P-reactor spilled over to a downstream decanter (IBC 6 in Fig. 1 ), which in turn spilled over to the wastewater treatment of the plant.

In a further adjustment (Phase 4) the $25 \mu \mathrm{m}$ filter on the third IBC was changed for a washable $60 \mu \mathrm{m}$ candle filter and a UV-C lamp (Clean Pond UV-C 18 Watt from Velda) which was added to reduce microbial growth. Circulation was performed with a Newa Jet $R 2300$ aquarium pump. This prefiltered nitrified effluent was then sent over an UF unit (Ekopak, Belgium) that was controlled via level regulators. The UF unit was equipped with a module from BASF (Dizzer P 4040-6.0). A filtration cycle

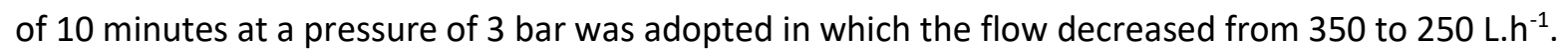




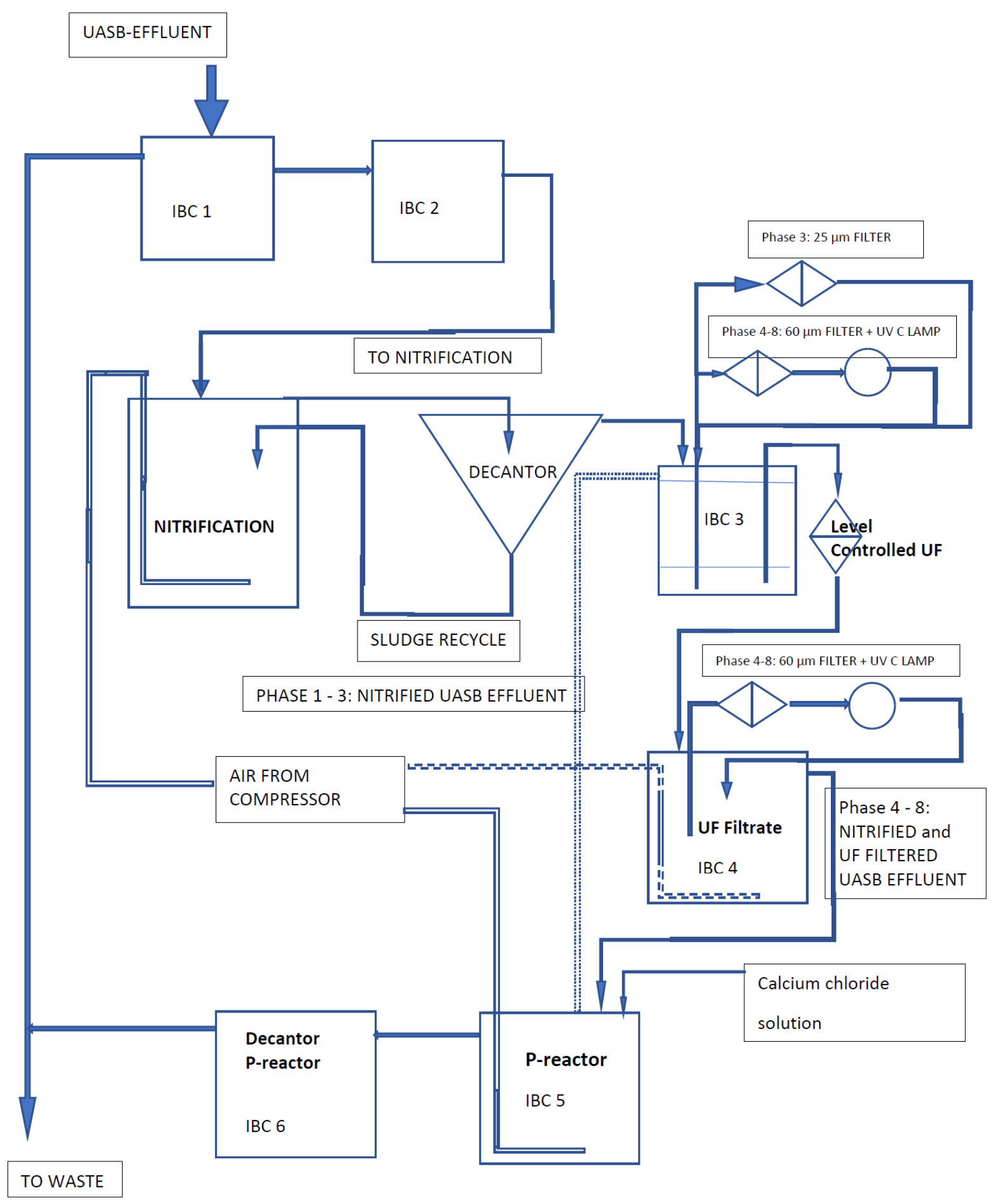

Fig. 1. Lay out of the finally constructed pilot scale installation for phosphate recovery as it was used in phases 4 to 8 of the experiment. Dotted line: short cut to the P-reactor in the experiments 1 to 3 . In phase 7 and 8 the UF-filtrate was continuously pumped to the P-reactor. In phase 8 of the experiment the UF-filtrate was occasionally also aerated, which is indicated with the dashed line. The back wash of the UF, either to the nitrification reactor (phases 1 to 7) or to the waste (phase 8 ) is not indicated for simplicity.

The UF filtrate produced was collected in a fourth IBC and was also recirculated over a (washable) cartridge filter of $60 \mu \mathrm{m}$ and a UV-C lamp with a recirculation pump (all idem as above).This UV-C treated UF filtrate spilled over to the fifth IBC that was used as P reactor. The backwash ( $30 \mathrm{sec} .1200$ $\mathrm{L.h}^{-1}$ ) was sent to the nitrification reactor. Inherent to the discontinuous functioning of the UF system, the spilling over of the UF filtrate to the P reactor was also discontinuous. On the contrary the flow 
rate of the calcium chloride solution was constant. The reactor was also vigorously mixed every 2.5 hours for 5 minutes.

In phase 5, it was investigated if the phosphate could be recovered as calcium phosphate from the 60 $\mu \mathrm{m}$ prefiltered effluent in a lamella separator build according to Alvaro et al. [25]. The filtrate and the calcium chloride were fed to the last compartment before the settling unit; this compartment was also mechanical mixed.

Compared to the set up in phase 4, two more adaptions to the system were performed. In phases 6 and 7 , the P-reactor was aerated and continuously mixed by a submerge placed fountain pump (Velda model 2000). In experiment 7 the ultra-filtrated effluent was continuously pumped to the P-reactor with a peristaltic pump at a flow rate of 40 L.h.'

Using the last setup, in phase 8, different factors such as intensity, continuity and place of aeration as well as variation of the HRT in the P-reactor were tested for their possible role in the development of color at the same $\mathrm{Ca} / \mathrm{P}$ ratio of about 4.0. To avoid accumulation of colored substances in the whole system the backwash of the UF was sent to the waste.

\section{c. Analytical procedures}

Samples of the UASB effluent, the nitrified effluent, the ultrafiltrate and the effluent of the P-reactor were taken 3 times a week for analysis. The following parameters were analysed: $\mathrm{pH}$, conductivity and chloride, nitrate, phosphate, sulphate, sodium, ammonium, potassium, calcium, magnesium, DIC and total organic carbon (TOC) concentration. For details see Monballiu et al. [26]. Metal ions, S (expressed as $\mathrm{SO}_{3}$ ) and $\mathrm{Si}$ (expressed as $\mathrm{SiO}_{2}$ ) in the precipitates were determined with an ICP-OES ICAP 6000 from Thermo Scientific. Phosphorus expressed as $\mathrm{P}_{2} \mathrm{O}_{5}$ was determined colorimetric as the phosphovanadomolybdate complex with a Skalar SAN System and the $\% \mathrm{P}_{2} \mathrm{O}_{5}$ citrate was determined according to EC regulation 2003/2003 of the European Parliament and of the Council relating to fertilizers. Elemental analysis of the precipitates was performed through scanning electron microscopy-based energy dispersive X-ray spectroscopy (SEM-EDX) using a Philips/FEI XL-30FEG. The samples were deposited on carbon tape and coated with a thin Au/Pd-layer using a JEOL auto fine coater (JFC-1300) to minimize sample charging during analysis. The composition was determined at 15 randomly selected points and averaged. X-ray diffraction (XRD) analysis were performed using either a STOE Stadi P high-throughput powder diffractometer in transmission mode and an image plate detector or a Malvern PANalytical Empyrean equipped with a PIXcel3D detector. In both cases CuK $\alpha$ radiation was used.

d. Drying and calcination of the precipitates

The water content was determined by drying in air at $105^{\circ} \mathrm{C}$ until constant weight.To oxidize and eliminate organic material the precipitates were heated at $550-600^{\circ} \mathrm{C}$ ( 6 hours). For full calcination with decomposition of calcium carbonate to calcium oxide $(\mathrm{CaO})$ and carbon dioxide $\left(\mathrm{CO}_{2}\right)$ the precipitate was additionally heated at $900{ }^{\circ} \mathrm{C}$ (6 hours).

e. Pilot scale preparation of phosphoric acid

The precipitates recovered from phases 2 and 7 of the experiment were combined and used in a pilot scale test for phosphoric acid production. The precipitate from phase 2 which had a large content of water (46 m\%) was first dried at $60{ }^{\circ} \mathrm{C}$ and was then mixed with the precipitate of phase $7(16 \mathrm{~m} \%$ water) to obtain 30 of $\mathrm{kg}$ of product that was subjected to the test. 
The test was carried out in the dihydrate modus with the final goal to obtain a phosphoric acid solution equivalent to $28 \mathrm{~m} \% \mathrm{P}_{2} \mathrm{O}_{5}$; see reaction 1 . At the start a slurry was prepared with $35 \mathrm{~m} \%$ gypsum $\left(\mathrm{CaSO}_{4} .2 \mathrm{H}_{2} \mathrm{O}\right)$ in $28 \mathrm{~m} \%$ phosphoric acid $\left(\mathrm{H}_{3} \mathrm{PO}_{4}\right)$. To this slurry was added, at $76^{\circ} \mathrm{C}$, the precipitate $(0.96$ $\left.\mathrm{kg} \cdot \mathrm{h}^{-1}\right)$ and $98 \%$ sulphuric acid $\left(\mathrm{H}_{2} \mathrm{SO}_{4} ; 0.78 \mathrm{~kg} \cdot \mathrm{h}^{-1}\right)$; the recirculation rate was $1.9 \mathrm{~kg} \cdot \mathrm{h}^{-1}$.

3. Results and discussion

\section{A Starting UASB effluent and nitrification}

The experiment lasted for 1 year and 2 months which was only interrupted by summer and winter production stops; the active experimental time was over 1 year. During that long period there was some variation in the composition of the used UASB effluent; see Fig. 2 and Table 1. The phosphate-P concentration was about $53 \mathrm{mg} \cdot \mathrm{L}^{-1}\left(1.7 \mathrm{mmol} . \mathrm{L}^{-1}\right)$. The $\mathrm{Ca}^{2+}$ concentration with values around 63 $\mathrm{mg} . \mathrm{L}^{-1}$ (1.6 mmol.L $\left.{ }^{1}\right)$ varied somewhat more, which has to do with the composition of the used process water which was reverse osmosis (RO) water supplemented with tap water depending on the needs [27]. The molar $\mathrm{Ca} / \mathrm{P}$ ratio in the influent was about $0.66 \pm 0.24$.

A further characteristic of the UASB effluent is the neutral pH $(7.51 \pm 0.15)$ and the high concentration of $\mathrm{Mg}^{2+}\left(59.6 \pm 12.9 \mathrm{mg} \cdot \mathrm{L}^{-1}=2.48 \pm 0.53 \mathrm{mmol} . \mathrm{L}^{-1}\right)$ and K$\left(1564 \pm 212 \mathrm{mg}\right.$. L ${ }^{-1}=40 \pm 5$ mmol. $\left.\mathrm{L}^{-1}\right)$. The ammonium concentration was $25 \pm 6 \mathrm{mmol} . \mathrm{L}^{-1}$. Ammonium was completely removed during nitrification; see Fig. 3. The conversion ratio $\mathrm{NH}_{4}{ }^{+}-\mathrm{N} / \mathrm{NO}_{3}{ }^{-} \mathrm{N}$ was about 1.1, indicating that some nitrogen was lost, probably by denitrification.

Especially in the second part of the experiment the concentration of dissolved inorganic carbon with

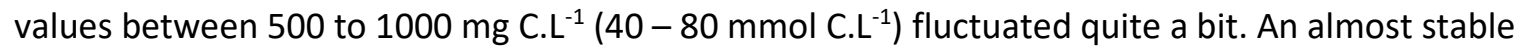
effluent concentration of DIC (10 -15 mmol. $\left.\mathrm{L}^{-1}\right)$ is nevertheless obtained. In general, the $\mathrm{pH}$ did not change that much; the effluent $\mathrm{pH}$ was $7.44 \pm 0.33$. The average ratio DIC removed over ammonium removed is $2.56 \pm 0.33$, indicating that in addition to reaction (5), probably part of the DIC is also blown out. With an average removed ammonium concentration of about $25 \mathrm{mmol}^{-1}$ the expected DIC removal is $50 \mathrm{mmol} . \mathrm{L}^{-1}$, which is e.g. the case in the middle of the experiment.

Table 1 : average value and standard deviation of some parameters of the incoming UASB effluent.

\begin{tabular}{|c|c|c|}
\hline $\mathrm{pH}$ & $(-)$ & $7.51 \pm 0.15$ \\
\hline $\mathrm{NH}_{4}{ }^{+} \mathrm{N}$ & $\mathrm{mg} / \mathrm{L}$ & $350 \pm 78$ \\
\hline $\mathrm{K}^{+}$ & $\mathrm{mg} / \mathrm{L}$ & $1564 \pm 212$ \\
\hline $\mathrm{Ca}^{2+}$ & $\mathrm{mg} / \mathrm{L}$ & $62.8 \pm 19.4$ \\
\hline $\mathrm{Mg}^{2+}$ & $\mathrm{mg} / \mathrm{L}$ & $59.6 \pm 12.9$ \\
\hline $\mathrm{PO}_{4}{ }^{3-} \mathrm{P}$ & $\mathrm{mg} \mathrm{P} / \mathrm{L}$ & $53.10 \pm 8.95$ \\
\hline $\mathrm{Cl}$ & $\mathrm{mg} / \mathrm{L}$ & $332.2 \pm 18.6$ \\
\hline $\mathrm{DIC}$ & $\mathrm{mg} \mathrm{C} / \mathrm{L}$ & $731 \pm 156$ \\
\hline $\mathrm{TOC}$ & $\mathrm{mg} \mathrm{C} / \mathrm{L}$ & $221.8 \pm 88.3$ \\
\hline $\mathrm{Ca} / \mathrm{P}$ & $(-)$ & $0.94 \pm 0.32$ \\
\hline $\mathrm{Ca} / \mathrm{Mg}$ & $(-)$ & 0.660 .24 \\
\hline
\end{tabular}




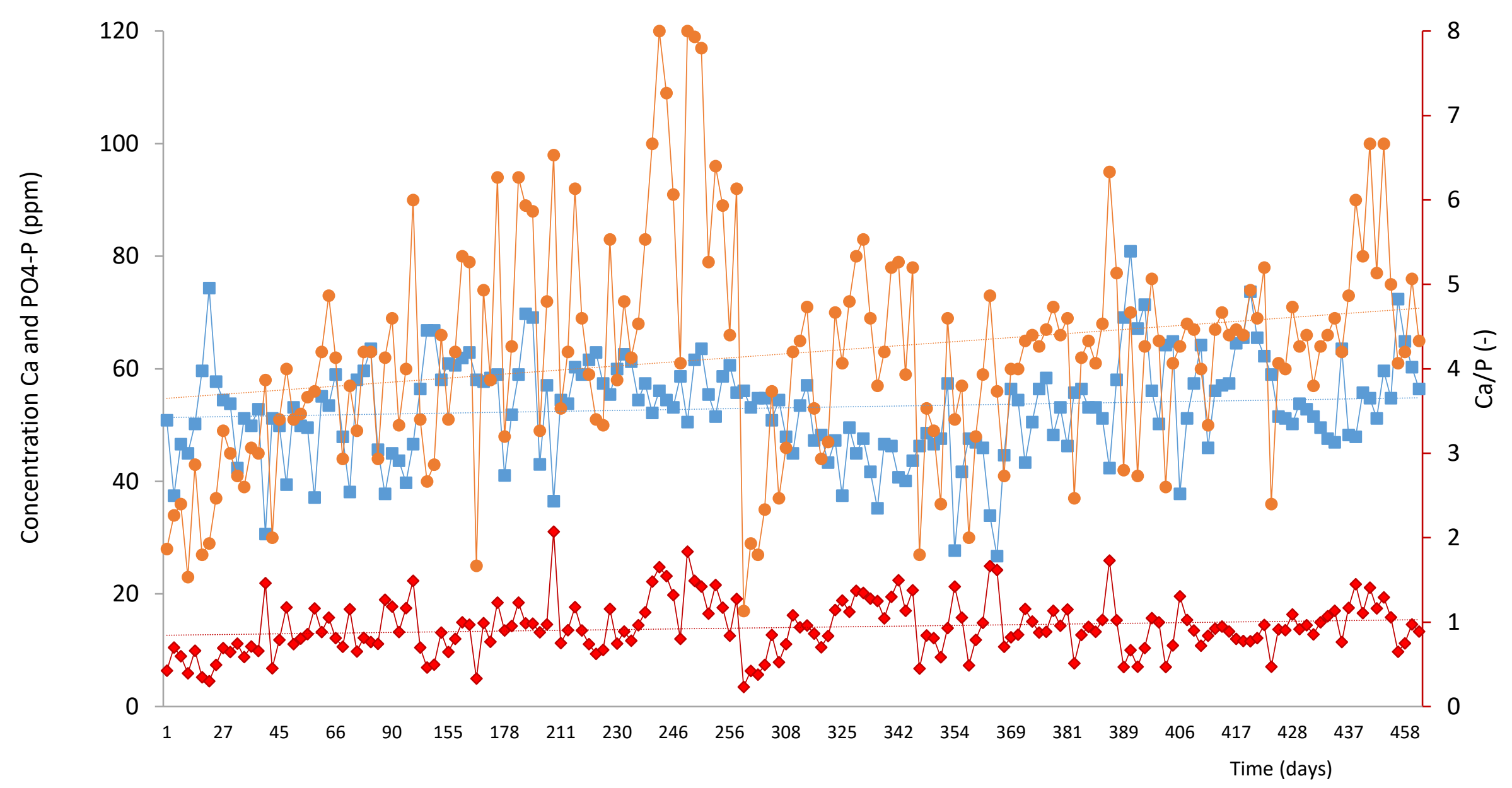

Fig. 2. Course of the calcium (orange circles) and phosphate (blue squares) concentration and the resulting $\mathrm{Ca} / \mathrm{P}$ ratio (red diamonds) along the experiment. 


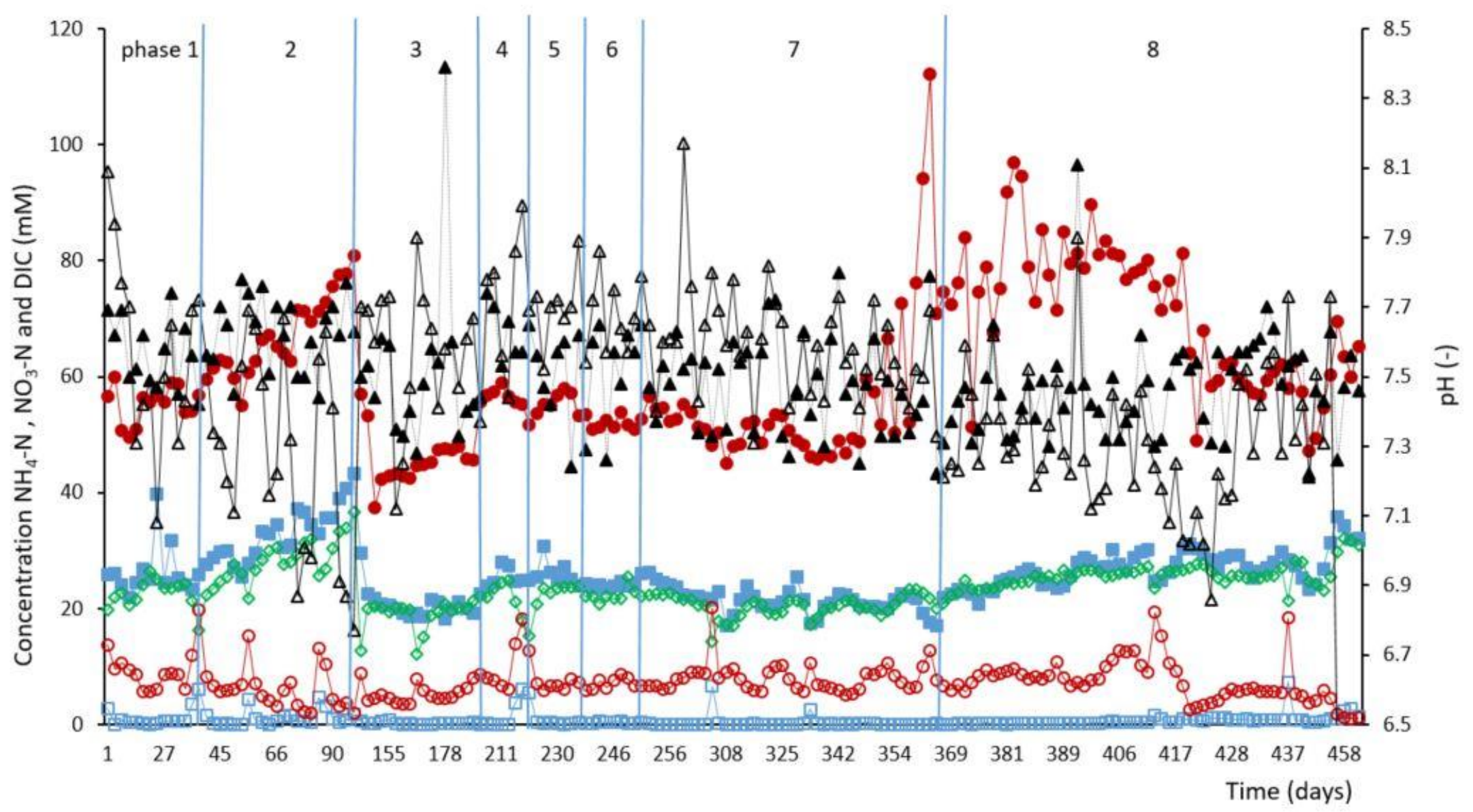

Fig. 3. Course of pH (black full triangles), DIC (red, full circles) and ammonium-N (blue, full squares) in the influent and pH (black open triangles, DIC (red open circles), ammonium-N (blue, open squares) and nitrate-N (green open diamonds) in the effluent of the nitrification reactor. Indicated are as well the several phases of the experiment. 


\section{B Phosphate recovery as calcium phosphate}

Initially the setup was as simple as possible. From the start of the experiment on, the sedimentation of the sludge in the decanter of the reactor was a problem, especially when the temperature increased, which may have to do with gas formation during some denitrification in static parts of the decanter; the data above indeed indicated that some denitrification occurred. The effluent of the decanter was not directly fed to the reactor for phosphate removal but was intermediately stored in a downstream IBC (IBC 3 in Fig. 1) for sedimentation of the sludge that spilled over from the decanter. Initially this IBC spilled over in the P-reactor (short cut - dotted line in Fig. 1) and the further adjustments to the system are mostly attempts to reduce the amount of organic material that enters the P-reactor. The further adjustments, among them variations in the used molar $\mathrm{Ca} / \mathrm{P}$ ratio in the P-reactor and the type of mixing of and feeding to the P-reactor, are intended to improve or facilitate precipitation or crystallization of the calcium phosphate. As such the whole experiment can be divided in eight consecutive phases; see Fig. 3. Table 2 summarizes the experimental conditions during the recovery of phosphate and Table 3 summarizes the characteristics of the recovered precipitates.

\section{Effect of added Ca/P ratio on the recovery}

The recovery of phosphate in the different phases varies between 77 and $90 \%$. In Fig. 4 the recovery in the different phases of the experiment is represented as function of the added $\mathrm{Ca} / \mathrm{P}$ ratio and the $\mathrm{pH}$ of the effluent of the $\mathrm{P}$ reactor which is also the actual $\mathrm{pH}$ in the reactor. The percent recovery of phosphate is calculated from the concentrations in the influent of the P-reactor and the effluent of the decanter after the P-reactor; see Table 2.

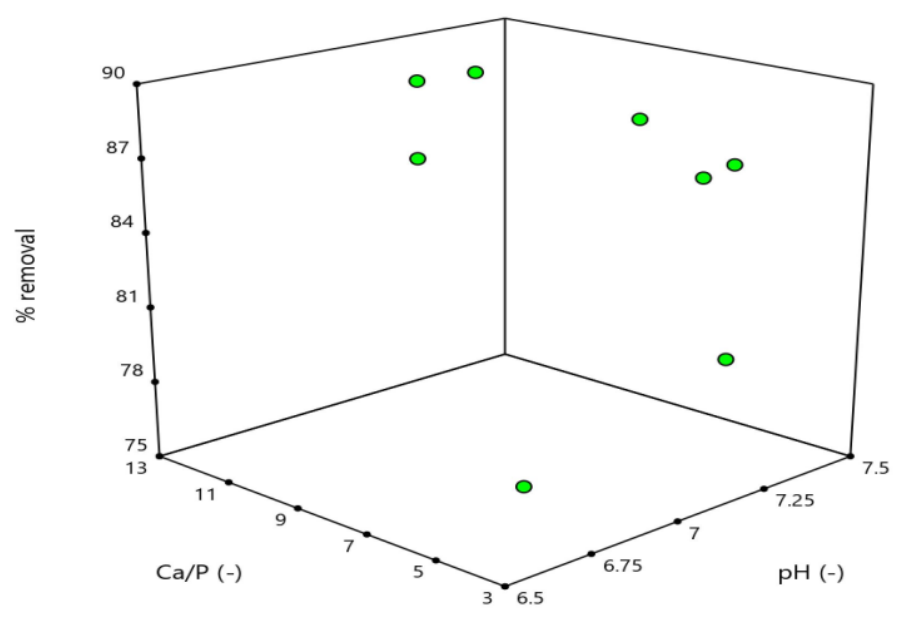

Fig. 4. Phosphate removal during the different phases of the pilot scale experiment as function of the applied $\mathrm{Ca} / \mathrm{P}$ ratio and the $\mathrm{pH}$ of (the effluent of) the P-reactor

From Table 2 and Fig. 4 it is obvious that increasing the molar ratio of added calcium relative to the endogenous concentration of phosphate promotes phosphate precipitation, an observation which agrees with previous ones on lab scale $[20,26]$. In Fig. 4 the positive effect of small increases in pH can also be observed. It is indeed known that increasing the $\mathrm{pH}$ stimulates calcium phosphate precipitation [14]. In phases 2 and 8 (final conc. $14.3 \pm 11.9$ and $11.6 \pm 4.2$ ) for a molar $\mathrm{Ca} / \mathrm{P}$ ratio of about 4 , the recovery was about $80 \%$, in phases 4 and 7 (final conc. $6.7 \pm 8.1$ and $5.6 \pm 3.8$ ) with ratios of 7.2 , the recovery was $85-87 \%$ and for a ratio of about 9 in phase 3 (final conc. $6.4 \pm 4.0$ ) the recovery was about $90 \%$. In phase 6 the removal is considerably lower; see further. These recoveries are in line with those obtained in a CSTR at lab scale $[16,20]$, but were in general 
Table 2: Overview of the different phases of the experiment, effect on $\mathrm{pH}$ and DIC (average \pm STDEV) and effect on phosphate removal

\begin{tabular}{|c|c|c|c|c|c|c|c|c|c|c|c|c|c|c|}
\hline \multirow[t]{2}{*}{ PHASE } & \multirow[t]{2}{*}{ DURATION } & \multirow{2}{*}{$\begin{array}{c}\text { Filtratio } \\
\mathbf{n}\end{array}$} & \multirow{2}{*}{ Feed to reactor } & \multirow{2}{*}{$\begin{array}{l}\mathrm{Ca} / \mathrm{P} \text { ratio } \\
\text { added }\end{array}$} & \multicolumn{3}{|c|}{$\mathrm{pH}$} & \multicolumn{3}{|c|}{ DIC } & \multirow{2}{*}{$\begin{array}{l}\text { Stirring } \\
\text { P-reactor }\end{array}$} & \multicolumn{3}{|c|}{ PHOSPHATE_P } \\
\hline & & & & & in & out & $\Delta$ & in & out & $\Delta$ & & INITIAL & FINAL & $\%$ removal \\
\hline 1 & 1.5 months & NO & $\begin{array}{c}\text { Continuous } \\
\text { overflow }\end{array}$ & $4.7 \pm 0.5$ & $7.5 \pm 0.3$ & $7.3 \pm 0.5$ & 0.2 & $104 \pm 42$ & $70 \pm 31$ & $34 \pm 29$ & $\begin{array}{c}\text { Mechanical } \\
\text { Continue }\end{array}$ & $55.0 \pm 6.1$ & $7.3 \pm 3.7$ & 87 \\
\hline 2 & 1.5 months & NO & $\begin{array}{c}\text { Continuous } \\
\text { overflow }\end{array}$ & $4.5 \pm 0.4$ & $7.3 \pm 0.3$ & $6.7 \pm 0.4$ & 0.6 & $68 \pm 48$ & $23 \pm 21$ & $45 \pm 34$ & $\begin{array}{c}\text { Submersible } \\
\text { pump - } \\
\text { continue }\end{array}$ & $63.6 \pm 5.6$ & $14.3 \pm 11.9$ & 77 \\
\hline 3 & 1.5 months & $25 \mu \mathrm{m}$ & $\begin{array}{c}\text { Continuous } \\
\text { overflow }\end{array}$ & $9.4 \pm 5.2$ & $7.6 \pm 0.2$ & $6.9 \pm 0.3$ & 0.7 & $66 \pm 18$ & $33 \pm 12$ & $33 \pm 15$ & $\begin{array}{c}\text { Submersible } \\
\text { pump } \\
\text { discontinue }\end{array}$ & $63.9 \pm 5.4$ & $6.4 \pm 4.0$ & 90 \\
\hline 4 & 1 month & $\begin{array}{l}60 \mu \mathrm{m} \\
+\mathrm{UF}\end{array}$ & $\begin{array}{l}\text { Discontinuous } \\
\text { control by UF }\end{array}$ & $7.2 \pm 1.7$ & $7.8 \pm 0.4$ & $7.5 \pm 0.4$ & 0.3 & $99 \pm 27$ & $83 \pm 11$ & $16 \pm 7$ & $\begin{array}{c}\text { Submersible. } \\
\text { pump } \\
\text { discount. }\end{array}$ & $55.2 \pm 7.9$ & $6.7 \pm 8.1$ & 85 \\
\hline 5 & 0.5 month & $60 \mu \mathrm{M}$ & $\begin{array}{l}\text { Cont. to } \\
\text { lamella } \\
\text { separator }\end{array}$ & $6.2 \pm 0.1$ & $7.7 \pm 0.6$ & $6.6 \pm 0.2$ & 1.1 & $80.4 \pm 8$ & $50 \pm 14$ & $31 \pm 19$ & $\begin{array}{c}\text { Mechanical } \\
\text { Continue }\end{array}$ & $62.3 \pm 2$ & $6.8 \pm 3.5$ & 89 \\
\hline 6 & 0.5 month & $\begin{array}{l}60 \mu \mathrm{m} \\
+ \text { UF } \\
+ \text { UV C }\end{array}$ & $\begin{array}{l}\text { Discontinuous } \\
\text { control by UF }\end{array}$ & $12.9 \pm 5.9$ & $7.9 \pm 0.1$ & $7.4 \pm 0.3$ & 0.5 & $77 \pm 29$ & $43 \pm 11$ & $34 \pm 27$ & $\begin{array}{c}\text { Pond } \\
\text { Aerator } \\
\text { continue }\end{array}$ & $56.8 \pm 4.6$ & $7.0 \pm 8.7$ & 88 \\
\hline 7 & 2.5 months & $\begin{array}{c}60 \mu \mathrm{m} \\
+\mathrm{UF} \\
+ \text { UV C }\end{array}$ & $\begin{array}{c}\text { Continue with } \\
\text { peristaltic } \\
\text { pump }\end{array}$ & $\begin{array}{c}7.2 \pm 2.8 \\
\text { Average of } \\
\text { two phases }\end{array}$ & $7.6 \pm 0.2$ & $7.3 \pm 0.2$ & 0.3 & $89 \pm 35$ & $61 \pm 20$ & $28 \pm 22$ & $\begin{array}{c}\text { Pond } \\
\text { Aerator } \\
\text { continue }\end{array}$ & $46.1 \pm 5.3$ & $5.6 \pm 3.8$ & 88 \\
\hline 8 & 3 months & $\begin{array}{c}60 \mu \mathrm{m} \\
+\mathrm{UF} \\
+\mathrm{UVC}\end{array}$ & $\begin{array}{c}\text { Continue with } \\
\text { peristaltic } \\
\text { pump }\end{array}$ & $3.9 \pm 0.5$ & $7.7 \pm 0.3$ & $7.2 \pm 0.2$ & 0.5 & $77 \pm 39$ & $41 \pm 22$ & $36 \pm 28$ & $\begin{array}{l}\text { Pond aerator } \\
\text { or compressed } \\
\text { air continue or } \\
\text { discontinue }\end{array}$ & $58.9 \pm 7.4$ & $11.6 \pm 4.2$ & 80 \\
\hline
\end{tabular}


Table 3: Properties of the different precipitates that were analysed from the different phases of the experiment.

\begin{tabular}{|c|c|c|c|c|c|c|c|c|c|c|c|c|c|}
\hline \multirow[t]{2}{*}{ Phase } & \multirow[t]{2}{*}{ Duration } & \multicolumn{2}{|c|}{ PREPARATION } & \multicolumn{6}{|c|}{ CHEMICAL COMPOSITION } & \multicolumn{4}{|c|}{ MOLECULAR COMPOSITION RELATIVE TO PHOSPHORUS } \\
\hline & & \begin{tabular}{|l|} 
Precipitate of \\
reactor and \\
decanter together
\end{tabular} & Washing and Dying & $\begin{array}{c}\mathrm{P} \\
\left(\% \mathrm{P}_{2} \mathrm{O}_{5}\right)\end{array}$ & $\begin{array}{c}\mathrm{Ca} \\
(\% \mathrm{CaO})\end{array}$ & $\begin{array}{c}\mathrm{Mg} \\
(\% \mathrm{MgO})\end{array}$ & $\begin{array}{c}\mathrm{K} \\
(\% \mathrm{~K} 20)\end{array}$ & $\begin{array}{c}\mathrm{Cl} \\
\mathrm{ppm}\end{array}$ & $\begin{array}{c}\text { C total(\%) } \\
\text { Org. mat (\%) }\end{array}$ & $\mathrm{Ca}$ & $\mathrm{Mg}$ & K & $\mathrm{Cl}$ \\
\hline 1 & 1.5 months & YES & $\begin{array}{l}\text { Not washed } \\
\text { Dried in the air }\end{array}$ & 21 & 26 & 0.42 & 1.55 & 8720 & $\begin{array}{c}6.86 \\
23\end{array}$ & 2.02 & 0.04 & 0.12 & \\
\hline 2 & 1.5 months & YES & $\begin{array}{l}\text { Dried in the air } \\
\text { Calcination }\end{array}$ & $\begin{array}{l}34.9 \\
39.0\end{array}$ & 43.2 & 0.47 & 1.32 & 7890 & $\begin{array}{l}5.36 \\
15\end{array}$ & 1.85 & 0.04 & 0.16 & \\
\hline 3* & 1.5 months & NO & $\begin{array}{l}\text { Washed R0 water } \\
\text { Dried in oven } \\
\text { at } 70^{\circ} \mathrm{C}\end{array}$ & 32.4 & 33.9 & 0.43 & 1.13 & 13800 & 6.33 & 1.64 & 0.02 & 0.06 & 0.77 \\
\hline 4 & 1 month & No & $\begin{array}{l}\text { Washed RO water } \\
\text { Dried in oven } \\
\text { at } 70^{\circ} \mathrm{C}\end{array}$ & 35.8 & 45.8 & 0.28 & 0.14 & 1490 & 2.90 & 1.80 & 0.01 & 0.01 & 0.09 \\
\hline 5 & 0.5 month & I & $\begin{array}{c}\text { (Washed with RO water) } \\
\text { To many TOC }\end{array}$ & ND & ND & ND & ND & ND & ND & ND & ND & ND & ND \\
\hline 6 & 0.5 month & $\begin{array}{c}\text { NO } \\
\text { Analysed } \\
\text { separately }\end{array}$ & \begin{tabular}{|l|l}
$\begin{array}{l}\text { Washed: RO water } \\
\text { Dried in boiler room }\end{array}$ & $R$. \\
& Dec
\end{tabular} & $\begin{array}{l}35.5 \\
35.5\end{array}$ & $\begin{array}{l}42.9 \\
43.4\end{array}$ & $\begin{array}{l}1.58 \\
0.74\end{array}$ & $\begin{array}{l}0.13 \\
0.58\end{array}$ & $\begin{array}{l}954 \\
2170\end{array}$ & $\begin{array}{l}2.26 \\
2.70\end{array}$ & $\begin{array}{l}1.62 \\
1.75\end{array}$ & $\begin{array}{l}0.07 \\
0.03\end{array}$ & $\begin{array}{l}0.00 \\
0.03\end{array}$ & $\begin{array}{l}0.12 \\
0.00\end{array}$ \\
\hline 7 & 2.5 months & YES & $\begin{array}{l}\text { Washed RO water } \\
\text { Dried in boiler room }\end{array}$ & 37.5 & 47.1 & 0.65 & 0.11 & 495 & $\begin{array}{l}3.81 \\
11.8\end{array}$ & 1.80 & 0.02 & ND & ND \\
\hline 8 & 3 months & YES & $\begin{array}{l}\text { Washed: RO water } \\
\text { Dried } 105^{\circ} \mathrm{C} \\
\text { Calcinated } 600^{\circ} \mathrm{C} \\
\text { Calcinated } 900^{\circ} \mathrm{C}\end{array}$ & $\begin{array}{l}39.7 \\
42.8 \\
44.0\end{array}$ & $\begin{array}{l}48.1 \\
\\
51.5 \\
52.4\end{array}$ & $\begin{array}{l}0.50 \\
\\
0.54 \\
0.54\end{array}$ & $\begin{array}{l}0.07 \\
0.08 \\
0.08\end{array}$ & $\begin{array}{l}469 \\
\\
504 \\
658\end{array}$ & $\begin{array}{l}2.01 \\
7.0 \\
0.29 \\
0.02\end{array}$ & ND & ND & ND & ND \\
\hline
\end{tabular}


somewhat lower. E.g., at an added Ca/P ratio of about 4 in this work a recovery of $80 \%$ is obtained while at lab scale this degree of phosphate removal was already obtained with a total $\mathrm{Ca} / \mathrm{P}$ ratio of 4 [20].

As an illustration of the effect of the added $\mathrm{Ca} / \mathrm{P}$ ratio, Fig. 5 gives the result of phase 7, which lasted for 2.5 months and which itself can be divided into two separate phases based on the molar $\mathrm{Ca} / \mathrm{P}$ ratio added to the reactor. In the first part the added $\mathrm{Ca} / \mathrm{P}$ ratio was $10.2 \pm 1.8$ and the residual phosphate concentration was $3.1 \pm 1.4 \mathrm{mg} \cdot \mathrm{L}^{-1}$, an average recovery of $93 \%$. In the second part the $\mathrm{Ca} / \mathrm{P}$ ratio was $4.9 \pm 0.4$ which resulted in a final phosphate concentration of $7.6 \pm 3.9 \mathrm{mg} . \mathrm{L}^{-1}$; the average removal was $82 \%$. Halving the added amount of calcium as calcium chloride resulted thus in a decrease of the phosphate recovery by about $10 \%$.

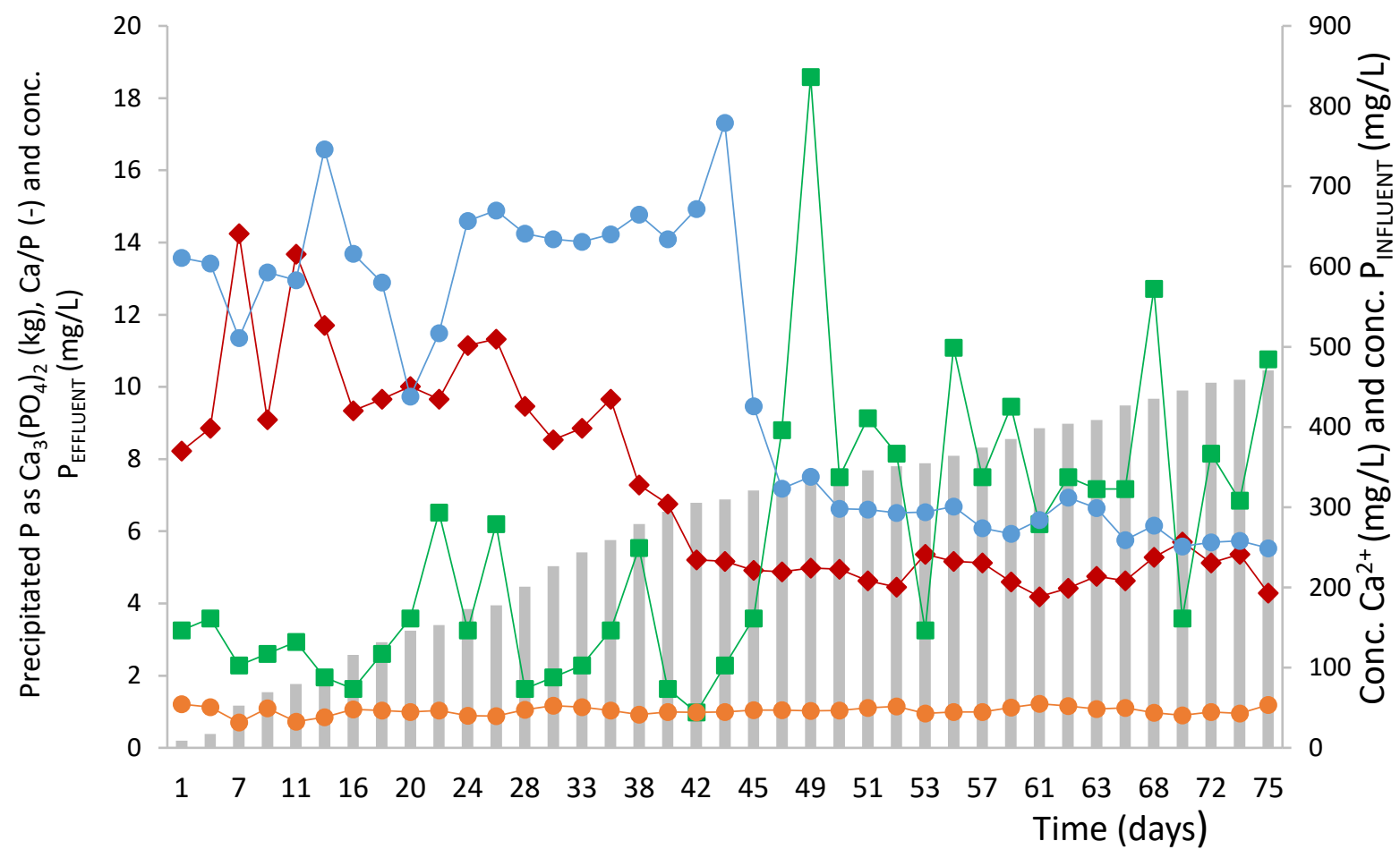

Fig. 5. Results for phase 7. Effect of decreasing the added Ca/P ratio from about 10 to about 5 (diamonds, red) on the phosphate concentration (squares, green) and the calcium concentration (circles, blue) in the effluent. Given as well is the phosphate concentration in the influent (orange; circles) and the calculated cumulative amount of phosphate that precipitated (grey bars).

A calculation based on the actual flow rate and the difference between the initial and the final phosphate concentration during phase 7 reveals that $10.45 \mathrm{~kg}$ of calcium phosphate precipitated in the reactor and the downstream decanter. After collecting and drying (about $40{ }^{\circ} \mathrm{C}$ ) for one month, $16 \mathrm{~kg}$ of product was recovered. Based on the weight loss at $105^{\circ} \mathrm{C}$ and $600^{\circ} \mathrm{C}$, the water content was $16 \%$ and the content of organic material was $11 \%$. The net amount of inorganic material was thus $12 \mathrm{~kg}$, which is somewhat higher than expected and which is most likely due to some contamination with calcium carbonate.

These results also show that this type of wastewater on which previously the recovery of phosphate as struvite was already implemented [6] is also suited for the recovery of phosphate as calcium phosphate.

Knowing that Belgian potato processors treat about four million tons of potatoes a year and that the mean phosphorous concentration is about $60 \mathrm{mg}$ per $100 \mathrm{~g}$, they receive together about 2400 tons of 
phosphorus [27]. If $75 \%$ of it would end up in the UASB effluent and about $75 \%$ of the latter would precipitate as calcium phosphate, a total of 6750 tons of calcium phosphate would be recovered.

\section{Effect of the precipitation of phosphate on the $\mathrm{pH}$ and concentration of DIC}

In all the phases of the experiment the $\mathrm{pH}$ decreased as result of the precipitation or crystallization of calcium phosphate; see Table 2. Although rather difficult to interpret because of the large standard deviations, there seems to be no real relationship between the percent removal of phosphate and the decrease in $\mathrm{pH}$ during the reaction. This may have to do with the remaining buffering capacity of the nitrified UASB effluent since this still contains about $10 \mathrm{mmol}^{-1} \mathrm{~L}^{-1} \mathrm{DIC}$.

According to reaction (7) the precipitation of 2 molecules of phosphate as calcium phosphate consumes three molecules of DIC. Starting from about $60 \mathrm{mg}$ phosphate-P per litre or about 2 mmol. $\mathrm{L}^{-1}$ and with an average recovery of $88 \%$, the expected consumption of DIC is thus 2.64 mmol. $\mathrm{L}^{-1}$ or about $32 \mathrm{mg} . \mathrm{L}^{-1}$. Table 2 gives for the several phases the DIC concentration in the feed of the reactor and in the effluent of the downstream decanter. The average difference shows indeed

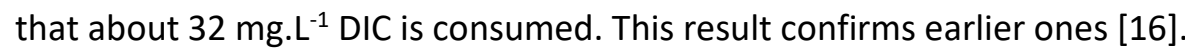

\section{Contaminations of the recovered precipitates}

The contamination of the precipitate with magnesium (Table 3) was in all cases limited. Relative to the molar amount of phosphate $P$, the contamination with magnesium was between 1 and $7 \%$. The contamination with calcium carbonate for which the $\mathrm{Ca} / \mathrm{P}$ ratio in the precipitate is a good indicator was also limited. The $\mathrm{Ca} / \mathrm{P}$ ratio in calcium phosphate and its recrystallized form HAP are respectively 1.5 and 1.67. The $\mathrm{Ca} / \mathrm{P}$ ratio in the different precipitates, except from phase 1 , was between 1.62 and 1.85; see Table 2. This rather limited contaminations are due to the relative low $\mathrm{pH}$. In this condition the precipitation of magnesium salts and calcium carbonate is limited $[20,26]$.The precipitates from phases 1 and 2 have the highest molar $\mathrm{Ca} / \mathrm{P}$ ratio. This samples were not washed, or at least not washed enough, as can be seen from the high chloride content; see Table 3. In these cases, the calcium chloride that is used to precipitate the phosphate as calcium phosphate may have contaminated the recovered product. Surprisingly this cannot be said for the precipitate of phase 3 , which has a large chloride content but a rather low $\mathrm{Ca} / \mathrm{P}$ ratio.

Despite the high potassium concentration in the effluent of the UASB (Table 1) the amount in the precipitates is low (Table 3), except for the first isolates which were also highly contaminated with organic material. Probably potassium adsorbs on the organic material and contaminated via this way the precipitates.

The fluffy precipitate of phase 8 was studied in detail. It was thoroughly washed with RO water and dried in air at $40{ }^{\circ} \mathrm{C}$ for two months; finally, $4.50 \mathrm{~kg}$ precipitate was recovered. The volumetric mass was $600 \mathrm{~g} . \mathrm{L}^{-1}$ and the loss on drying in air at $105^{\circ} \mathrm{C}$ for 24 hours was $3.3 \mathrm{~m} \%$. Table 4 gives some extra information on the chemical composition of the precipitates of phases 2,7 and 8 . The original precipitate of phase 8 fulfils Prayon's standards on aluminium, potassium, sodium, mercury, lead, cadmium, copper, titanium, ammonium and $\mathrm{SiO}_{2}(0.03 \mathrm{~m} \%)$. The low contamination with $\mathrm{Cd}$ is worthwhile to be stressed since $\mathrm{Cd}$ contamination of phosphorous ore and fertilizers caused $\mathrm{Cd}$ to be present in the soil of pharming land. It is this contamination that causes its presence in the UASB effluent of potato processors. 
Table 4: Composition of the precipitates isolated after phase 2, 7 and 8 after drying at $105 \mathrm{C}$ and after subsequent calcination of the precipitate of phase 8 respectively at $600^{\circ} \mathrm{C}$ and $900^{\circ} \mathrm{C}$. * : before drying

\begin{tabular}{|c|c|c|c|c|c|c|}
\hline & $\begin{array}{l}\text { Maximum } \\
\text { allowable } \\
\text { for } 15 \\
\mathrm{~m} \% \mathrm{P}_{2} \mathrm{O}_{5}\end{array}$ & $\begin{array}{c}\text { Precipitate } \\
\text { from } \\
\text { phase } 2\end{array}$ & $\begin{array}{c}\text { Precipitate } \\
\text { from } \\
\text { phase } 7\end{array}$ & $\begin{array}{c}\text { Precipitate } \\
\text { from } \\
\text { Phase } 8\end{array}$ & $\begin{array}{c}\text { Precipitate } \\
\text { from phase } 8 \\
\text { after } \\
\text { calcination } \\
\text { at } 600^{\circ} \mathrm{C}\end{array}$ & $\begin{array}{c}\text { Precipitate } \\
\text { from phase } 8 \\
\text { after } \\
\text { calcination } \\
\text { at } 900^{\circ} \mathrm{C}\end{array}$ \\
\hline $\mathrm{Al}$ as $\mathrm{Al}_{2} \mathrm{O}_{3} \%$ & 0.15 & 0.056 & 0.025 & 0.00616 & 0.0108 & 0.00915 \\
\hline As ppm & 3 & 0.318 & 11.31 & 0.0032 & 0.075 & 0.202 \\
\hline C total \% & & 5.36 & 3.81 & 2.01 & 0.292 & 0.015 \\
\hline $\mathrm{Ca}$ as $\mathrm{CaO} \%$ & & 43.2 & 47.1 & 48.1 & 51.5 & 52.4 \\
\hline Cd ppm & 1 & 1.71 & 0.584 & 0.252 & 0.276 & 0.296 \\
\hline $\mathrm{Cl} \mathrm{ppm}$ & 150 & 7890 & 495 & 469 & 504 & 658 \\
\hline $\mathrm{CO}_{2} \%$ (inorg. $\mathrm{C}$ ) & & 1.83 & 3.52 & 1.26 & 0.88 & 0.0242 \\
\hline $\mathrm{F} \%$ & & 0.047 & 0.116 & 0.138 & 0.119 & 0.126 \\
\hline $\mathrm{Fe}_{2} \mathrm{O}_{3} \%$ & & 0.312 & 0.137 & 0.0441 & 0.0495 & 0.0510 \\
\hline $\mathrm{H}_{2} \mathrm{O} 105^{\circ} \mathrm{C} \%$ & & $46 *$ & $16^{*}$ & 0.584 & 0.632 & 0.0963 \\
\hline $\mathrm{K}$ as $\mathrm{K}_{2} \mathrm{O} \%$ & 0.15 & 1.32 & 0.113 & 0.0684 & 0.0761 & 0.076 \\
\hline $\mathrm{Mg}$ as $\mathrm{MgO} \%$ & 0.04 & 0.472 & 0.653 & 0.499 & 0.539 & 0.537 \\
\hline $\mathrm{Na}$ as $\mathrm{Na}_{2} \mathrm{O} \mathrm{ppm}$ & 1500 & 0.119 & 0.063 & 0.114 & 0.122 & 0.122 \\
\hline $\mathrm{NH}_{4} \mathrm{ppm}$ & 3000 & 1280 & 753 & 473 & 221 & 4 \\
\hline $\mathrm{P}$ as $\mathrm{P}_{2} \mathrm{O}_{5} \mathrm{~T} \%$ & 15 & 34.9 & 37.5 & 39.7 & 42.8 & 44.0 \\
\hline $\mathrm{SiO}_{2} \%$ & $\begin{array}{l}\text { As low as } \\
\text { possible }\end{array}$ & 0.123 & 0.112 & 0.0304 & 0.0438 & 0.0396 \\
\hline $\mathrm{SO}_{3} \%$ & & 1.07 & 0.711 & 0.467 & 0.465 & 0.509 \\
\hline TOC \% & 0.15 & 4.86 & 2.80 & 1.67 & 0.05 & 0.01 \\
\hline $\mathrm{U}_{3} \mathrm{O}_{8} \mathrm{ppm}$ & & & & 1 & 1 & $<1$ \\
\hline
\end{tabular}

The chloride content in the dried precipitate was $469 \mathrm{mg} \cdot \mathrm{kg}^{-1}$, which is the lowest value from all isolated precipitates (see Table 3). Since the $\mathrm{P}_{2} \mathrm{O}_{5}$ content was $39.7 \mathrm{~m} \%$, this degree of contamination is just acceptable. Indeed, the allowed contamination is $150 \mathrm{mg} \cdot \mathrm{Kg}^{-1}$ for a $\mathrm{P}_{2} \mathrm{O}_{5}$ content of $15 \%$ (Table 4). The $\mathrm{CaO}$ amount of the precipitate is $48.1 \mathrm{~m} \%$ (Table 4) which corresponds to $34.4 \mathrm{~m} \% \mathrm{Ca}(0.86$ $\mathrm{mol} \mathrm{Ca} / 100 \mathrm{~g})$. Taken into consideration that the precipitate contains $39.7 \mathrm{~m} \% \mathrm{P}_{2} \mathrm{O}_{5}(=17.3 \mathrm{~m} \% \mathrm{P}=$ $0.56 \mathrm{~mol} P / 100 \mathrm{~g})$, the $\mathrm{Ca} / \mathrm{P}$ ratio for the precipitate can be calculated as 1.54 . If all the carbon dioxide $(1.26 \mathrm{~m} \%)$ would be present as calcium carbonate this would correspond to an amount of $2.86 \mathrm{~m} \%$ and $1.60 \mathrm{~m} \%$ calcium oxide. Corrected for the calculated amount of calcium oxide the $\mathrm{Ca} / \mathrm{P}$ ratio of precipitate is 1.48 or almost exactly what it should be for tricalcium diphosphate (1.5).

The precipitate however does not fulfil the criterion for magnesium set at the start of the experiments. With a concentration of $0.50 \mathrm{~m} \%$ expressed as $\mathrm{MgO}$ (or $5 \mathrm{~g}^{\mathrm{kg}} \mathrm{kg}^{-1}$ for a $\mathrm{P}_{2} \mathrm{O}_{5}$ content of 40 $\%$ ) the norm ( $\max 400 \mathrm{mg} \cdot \mathrm{kg}^{-1}$ for a $\mathrm{P}_{2} \mathrm{O}_{5}$ content of $15 \%$ ) is exceeded by a factor of 5 . This observation matches with the observed decrease of the concentration of magnesium ions in the $\mathrm{P}$ reactor: the incoming and outgoing magnesium concentration were in phase 8 of the experiment in average $72.4 \pm 10.2$ and $66.5 \pm 6.2 \mathrm{mg} \cdot \mathrm{L}^{-1}$ : a decrease of $5.90 \pm 6.9 \mathrm{mg} \cdot \mathrm{L}^{-1}$.

\section{Effect of filtration of the nitrified UASB effluent on organic contamination}

The effect of filtration of the nitrified UASB effluent on contamination with organic material can be seen in Table 3. After filtration over a $60 \mu \mathrm{m}$ filter the precipitate formed in a lamella separator (Phase 5) was highly contaminated with organic material. Only ultrafiltration (after prefiltration over 
a $60 \mu \mathrm{m}$ ) reduced significantly the contamination of the precipitates with organic material. The precipitate from phase 4 (only UF), phase 6 and 7 (UF and UV C) had 2.90, 2.26 and $3.81 \%$ total carbon for comparable $\mathrm{Ca} / \mathrm{P}$ ratios, which is much less than in the phases 1,2 and 3 . In the last 2 weeks of phase 7 , that lasted for 2.5 months, a problem occurred with a sealing ring in the UF installation. Probably this explains the enhanced percentage total carbon versus those of phase 4 and 6. The accidental contamination in phase 7 resulted in $11.8 \%$ contamination with organic material.

After phase 8 in which no obvious problems happened with the installation and the backwash of the ultrafiltration was not sent back to the waste, a precipitate was obtained with $2.0 \mathrm{~m} \%$ total carbon, which probably is the most indicative value to judge the influence of the UF filtration in combination with the UV C treatment. Nevertheless, this best precipitate still contained $7.0 \%$ organic material as determined from the loss on heating at $600^{\circ} \mathrm{C}$. This last phase also makes clear that besides suspended solids, also soluble organic material contributes to the impurity of the precipitates. The precipitate retained the colour that developed during its precipitation and was grinded in a mortar; see Fig. 6A. The actual TOC concentration is $1.67 \mathrm{~m} \%$, while the $\mathrm{P}_{2} \mathrm{O}_{5}$ content is $39.7 \mathrm{~m} \%$ (Table 4). For a $\mathrm{P}_{2} \mathrm{O}_{5}$ content of $15 \mathrm{~m} \%$ the maximal allowable concentration of TOC is $0.15 \mathrm{~m} \%$ and even if it is accepted that this maximum is $0.40 \mathrm{~m} \%$ for this high yielding $\mathrm{P}_{2} \mathrm{O}_{5}$ precipitate, this value is still exceeded by a factor four.

The rust brown colour of the precipitate suggests the presence of iron oxide; see Fig. 6A. However, it is very unlikely that the iron can be responsible for the discoloration at the determined low concentration of $0.04 \mathrm{~m} \%$ (expressed as $\mathrm{Fe}_{2} \mathrm{O}_{3}$; see table 4) .

The organic material present in these precipitates was not removed by the preceding nitrification and probably can be qualified as natural organic matter (NOM), a complex heterogeneous mixture of organic compounds. It was reported that NOM inhibits calcium phosphate precipitation by decreasing the concentration of free aqueous calcium ions and by blocking nucleation sites, both by interaction with its functional groups [28]. The experiments on the nitrified UASB effluent are carried out in the presence of a large excess of calcium ions ( $\mathrm{Ca} / \mathrm{P}$ ratio in minimally 4 ) and it is unlikely that the concentration of free calcium would be influenced significantly, but it is possible that NOM gets entrapped in the precipitates by interaction with lattice ions of the latter and gets incorporated in the calcium phosphate precipitate.

\section{Removing of organic and inorganic carbon from the precipitate by calcination}

On calcination at $600{ }^{\circ} \mathrm{C}$ of the precipitate from phase 8 for respectively 2,5 and 10 hours, $7.0,8.0$ and $8.6 \%$ weight loss was obtained. The remaining $4.35 \mathrm{~kg}$ was completely calcined at $600{ }^{\circ} \mathrm{C}$ for 6 hours; the effect on the colour can be seen in Fig. 6B. The product was grey in colour and has lost thus the typical colour that appeared during the precipitation in the P-reactor; it fulfilled the criterion for contamination by TOC. The $4.00 \mathrm{~kg}$ that remained was further calcinated at $900{ }^{\circ} \mathrm{C}$, also for 6 hours; this caused an additional weight loss of $2.0 \%$, so that finally $3.92 \mathrm{~kg}$ of a white product was obtained; see Fig. 6C. The effect on the chemical composition is seen in Table 4.

The increase in $\mathrm{m} \% \mathrm{CaO}$ and $\mathrm{P}_{2} \mathrm{O}_{5}$ after calcination at $600{ }^{\circ} \mathrm{C}$ and $900{ }^{\circ} \mathrm{C}$ reflects the increase in concentration by the decomposition of accompanying organic and inorganic material. The molar $\mathrm{Ca} / \mathrm{P}$ ratio of the precipitates was in both cases 1.52 . Calcination at $600{ }^{\circ} \mathrm{C}$ reduced the total carbon by $85 \%$ and the TOC reduced by $97 \%$, while the $\% \mathrm{CO}_{2}$ was only reduced by $30 \%$. This step thus almost completely removed all organic material. The further calcination at $900{ }^{\circ} \mathrm{C}$ resulted in an almost complete removal of carbon dioxide (final concentration $0.04 \mathrm{~m} \%$ ), while the $\mathrm{m} \%$ total carbon further decreased to $0.02 \mathrm{~m} \%$. This result shows that most of the inorganic carbon is decomposed at 
$900{ }^{\circ} \mathrm{C}$. At the same time the gray colour disappeared, a discoloration that apparently was due to the contamination of a combination of some organic material and calcium carbonate; Fig. 6C.

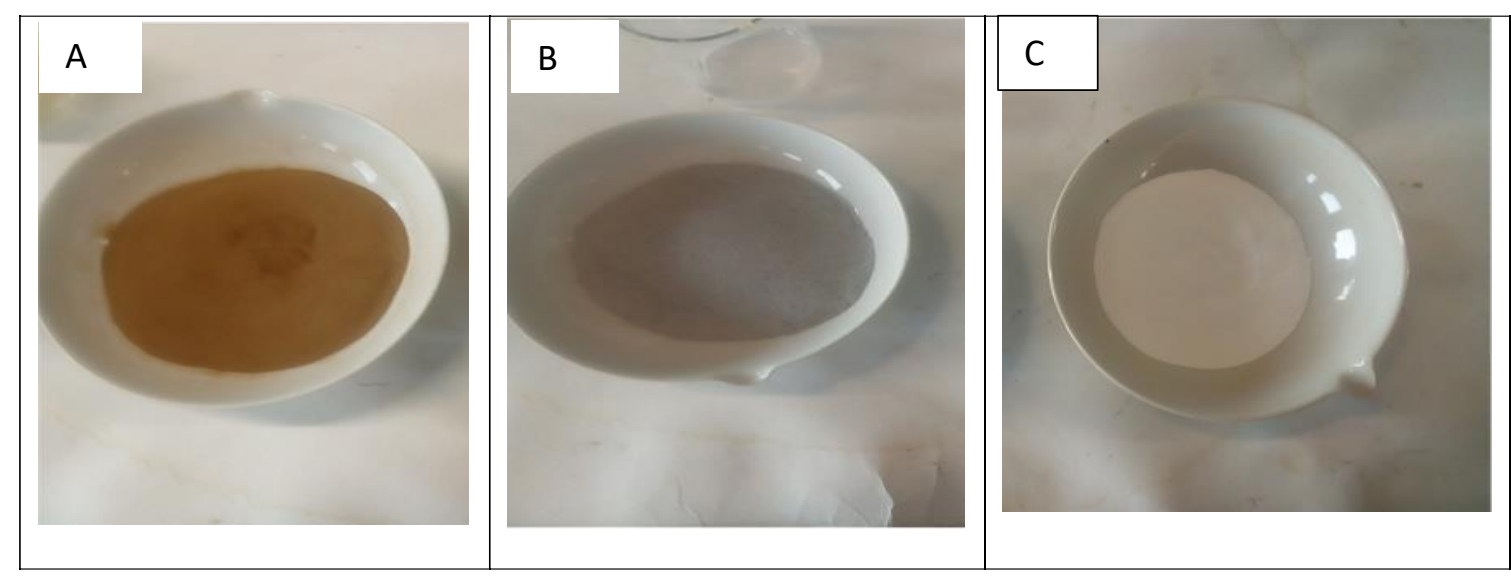

Fig. 6. Evolution of the visual aspect of the precipitate isolated from phase 8. A: precipitate dried at $108^{\circ} ; \mathbf{B}^{\circ}$ after heating/calcination at $600^{\circ} \mathrm{C}$; C: after calcination at $900^{\circ} \mathrm{C}$.

Table 5: Composition (in Atom\%) of the precipitate of phase 8 of the experiment after calcination at $900{ }^{\circ} \mathrm{C}$.

\begin{tabular}{|c|c|}
\hline Element & Atom\% \\
\hline $\mathrm{C}$ & $01.84 \pm 0.90$ \\
\hline $\mathrm{O}$ & $44.83 \pm 14.23$ \\
\hline $\mathrm{Na}$ & $0.41 \pm 0.39$ \\
\hline $\mathrm{Mg}$ & $0.67 \pm 0.45$ \\
\hline $\mathrm{Si}$ & $0.55 \pm 0.59$ \\
\hline $\mathrm{P}$ & $18.03 \pm 3.60$ \\
\hline $\mathrm{S}$ & $0.29 \pm 0.53$ \\
\hline $\mathrm{Cl}$ & $0.16 \pm 0.26$ \\
\hline $\mathrm{K}$ & $0.28 \pm 0.39$ \\
\hline $\mathrm{Ca}$ & $33.43 \pm 10.71$ \\
\hline
\end{tabular}

The result of an EDX analysis of the precipitate that underwent calcination at $900{ }^{\circ} \mathrm{C}$ is given in Table 5. The sample still contained about 2 Atom\% ( $1.84 \pm 0.90$ Atom \%) of $\mathrm{C}$, which was unexpected because as well organic and inorganic carbon were removed during the successive calcinations (Table 4). $98 \mathrm{Atom} \%$ of the bivalent cations is calcium; only $2 \mathrm{Atom} \%$ is magnesium; the atomic $\mathrm{Ca} / \mathrm{Mg}$ ratio is thus 49. The latter ratio is probably also valid for the original precipitate since both ions do not volatilize during calcination. The atomic ratio of $\mathrm{Ca} / \mathrm{P}$ is about $33.43 / 18.03$ or 1.85 , a clear indication for the presence of calcium phosphate (expected ratio 1.50) or HAP (expected ratio 1.67) that is contaminated with calcium oxide formed by decomposition of calcium carbonate. The residual contaminations with sodium, chloride and potassium are very low; see Table 5.

\section{Effect of feeding modus of the reactor}

In phases 4 and 6 the feeding to the reactor was discontinuous since the UF was regulated by the level controllers in IBC 3; Fig. 1. When the UF was not in action the reactor was not fed (13 hours) and the $\mathrm{Ca} / \mathrm{P}$ ratio in the reactor (IBC4) continuously increased; when the UF was active about 650 litre of UF-filtrate was fed to the reactor in about 2.5 hours and the $\mathrm{Ca} / \mathrm{P}$ ratio decreased. This cyclic alternation of the $\mathrm{Ca} / \mathrm{P}$ ratio in the reactor and thus of the saturation index of calcium phosphate did not result in a demonstrable improvement of the recovery, probably the opposite is true. In phase 6 in which an exceptionally high average molar $\mathrm{Ca} / \mathrm{P}$ ratio was used of $12.9 \pm 5.9$, the total recovery 
was only $88 \%$, about the same recovery as using simple overflow from the intermediate IBC 3 to the $\mathrm{P}$-reactor as in phase 1 using an added $\mathrm{Ca} / \mathrm{P}$ ratio of about 4.7.

\section{Effect of the mixing method of the P-reactor}

In phase 1 , the P-reactor was moderately mixed with a mechanical mixer. In phase 2 , the mixing was continuously and that vigorously that the temperature of the reactor increased to $35^{\circ} \mathrm{C}$. In phase 3,4 and 6 the reactor was therefore only mixed for 5 minutes with intervals of non-mixing of 2.5 hours. The data of Table 2 do not allow to claim that the differences in the way of mixing have influenced the results.

In phase 7 and 8 , the reactor was mixed by aeration with a pond aerator, or at a certain moment also with compressed air; see Fig. 1 and Table 6. This last method was introduced when it became clear from lab scale experiments that aeration promoted phosphate recovery as calcium phosphate by about $10 \%$ [26], but on pilot scale the effect was not that clear. E.g., in phase 8 (Ca/P ratio $=3.9 \pm$ $0.5 ; \mathrm{pH}=7.2 \pm 0.2)$ the recovery is $80 \%$ which is better than in phase $2(\mathrm{Ca} / \mathrm{P}=4.5 \pm 0.4 ; \mathrm{pH}=6.7 \pm$ 0.4 ) where the recovery was $77 \%$, but the $\mathrm{pH}$ was also a bit lower. The likely effect of aeration is explained by the fact that this contributes to expelling the carbon dioxide formed in reaction (7) from the P-reactor [26].

\section{Effect of variation in HRT and aeration}

In phase 8 the effect of different flow rates of ultra-filtered and nitrified UASB effluent to the Preactor and in combinations with variations in the aeration was investigated. As such phase 8 can be divided in 8 sub-phases; see Table 6. The HRT varied from 25 over 33 to 50 hours. The aeration in the reactor was or was not combined with a supplementary aeration in the feed (see Fig. 1-IBC 4) or was continuous or discontinuous. The different sub-phases of the experiment lasted minimally for 2 weeks, which was in each sub phase several times the HRT.

Table 6: Different combinations of HRT and ways of aeration used in phase 8

\begin{tabular}{ccccccccc}
\hline Sub-phase & 1 & 2 & 3 & 4 & 5 & 6 & 7 & 8 \\
\hline Duration (days) & $1-5$ & $6-20$ & $21-40$ & $41-46$ & $47-64$ & $65-80$ & $81-85$ & $86-92$ \\
\hline HRT (h) & 25 & 33 & 25 & 50 & 25 & 25 & 25 & 25 \\
\hline $\begin{array}{c}\text { Aeration } \\
\text { Reactor (\%) }\end{array}$ & 100 & 100 & 100 & 100 & 100 & 100 & 100 & 12,50 \\
\hline $\begin{array}{c}\text { Aeration feed } \\
\text { of the reactor (\%) }\end{array}$ & 0 & 0 & 0 & 100 & 100 & 100 & 0 & 0 \\
\hline
\end{tabular}

At the start, the P-reactor was continuously aerated, the feeding IBC was not aerated, and the HRT was 25 hours, which is the minimal value that can be obtained with the available equipment. The liquid in the P-reactor was initially not significantly coloured, but within 1-2 days a yellow-brown colour developed which was retained in all subsequent phases. Throughout the experiment a constant molar $\mathrm{Ca} / \mathrm{P}$ ratio of $3.9 \pm 0.5$ was maintained by applying a constant ratio of the flow rate of the feed to the reactor and the flow rate of the calcium chloride solution. The average phosphate-P load was $58.9 \pm 7.4$ and the final phosphate-P concentration was $11.6 \pm 4.2$ yielding an average phosphate recovery of $80 \%$. Fig. 7 shows that, at the molar Ca/P ratio used of about 4 , the phosphate-P concentration in the effluent of the reactor and decanter combination nicely follows the phosphate-P concentration of the influent of the reactor. This also shows that the used molar $\mathrm{Ca} / \mathrm{P}$ ratio cannot further be reduced if one wants to recover phosphate with a reasonable yield. At 
neutral $\mathrm{pH}$, as in this experiment, lower $\mathrm{Ca} / \mathrm{P}$ ratios would indeed result in low yields of calcium phosphate; e.g. with a $\mathrm{Ca} / \mathrm{P}$ ratio of 2 , the recovery of calcium phosphate was only about $15 \%$ [26].

Variations in the aeration did thus not influence the recovery, a result that agrees with previous ones [26]. The recovery was also not influenced by variations in the HRT indicating that the minimal HRT used was long enough for maximum precipitation. Enlarging the HRT did also not result in extra development of colour.

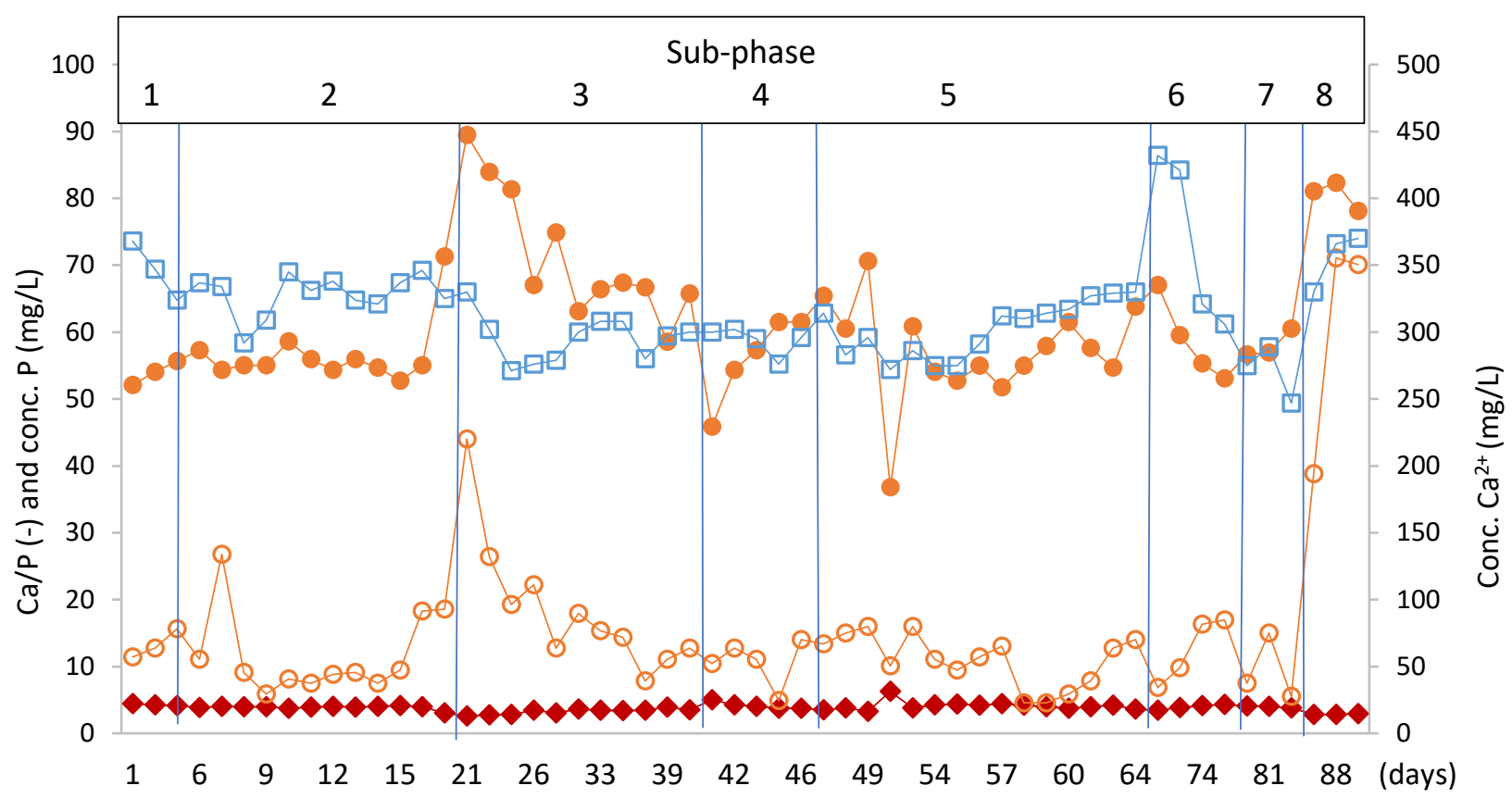

Fig. 7. Course of the phosphate-P concentration (orange full circles) and the $\mathrm{Ca} / \mathrm{P}$ ratio in the influent (red full diamonds) to the $\mathrm{P}$ - reactor in phase 8 of the experiment, as well as the $\mathrm{Ca}^{2+}$ ion concentration (blue open squares) and the phosphate-P concentration (orange open circles) in the effluent of the decanter put downstream the P-reactor.

From all the above it is obvious that NOM evokes a colour in the P-reactor. Apparently in all combinations above, the HRT (minimum 25 hours) was large enough to provoke the phenomenon. The UASB effluent that was treated is originating from a potato processor and it is known that potatoes contain polyphenols [29]. These polyphenols are in combination with polyphenol oxidases e.g. responsible for the discoloration when fresh potatoes are cut and are probably also responsible for the discoloration in the P-reactor. It is postulated that part of the NOM are polyphenols. This discoloration does however not occur during the nitrification or during the aeration of the ultrafiltrate. The added calcium chloride to the P-reactor somehow may play a role in the colour development.

\section{Precipitation and crystallisation}

The precipitation of calcium phosphate is a complex process that is influenced by e.g. $\mathrm{pH}, \mathrm{Ca} / \mathrm{P}$ ratio, the phosphate concentration, the temperature and the presence of impurities [28]. And, according to the Ostwald step rule on crystallization from a solution, thermodynamically unstable phases occur first and are then followed by a recrystallization to a thermodynamically more stable form [30]. Translated to the precipitation of calcium phosphate this suggests that first amorphous tricalcium diphosphate is formed followed by recrystallization to HAP. The practical impact of the above is that HAP mostly does not precipitate, even in conditions of high supersaturation, but that instead 
amorphous calcium phosphate may do so, which than reorganizes to HAP when the final pH is higher than 6.3 [24]. This explains why, over time the relative amount of HAP increases in precipitates of calcium phosphate

In the precipitate from phases 1 and 2, no crystallinity could be detected; apparently these precipitates contained too much organic material. In the precipitate recovered from phases 3, 4, 6 and 7 some crystallinity from HAP was found; see Fig. 8A for the precipitate of phase 7 . The precipitates of phases 6 and 7 which were aerated during the precipitation were somewhat more crystalline than the other. This enhanced crystallinity of the precipitates recovered after aeration of the P-reactor was observed previously [26].

During XRD, poor crystallinity causes peak broadening. A known method to increase crystallinity of HAP is heating the material at high temperature [31,32]. The crystallinity of the precipitate of phase 7 ameliorated after calcination at $600^{\circ} \mathrm{C}$, which removed the organic material; as can be seen from Fig. $8 \mathrm{~A}$. Figure $8 \mathrm{~B}$ gives the XRD of precipitate 8 that has been calcined at $900^{\circ} \mathrm{C}$, a treatment that both removes organic and inorganic carbon; see Table 4 . The 2-theta value of some of the peaks that can be attributed to HAP have moved a bit, but this is probably due to the presence of an impurity, which could not be identified, but it is not struvite nor monetite, calcite, aragonite or vaterite.
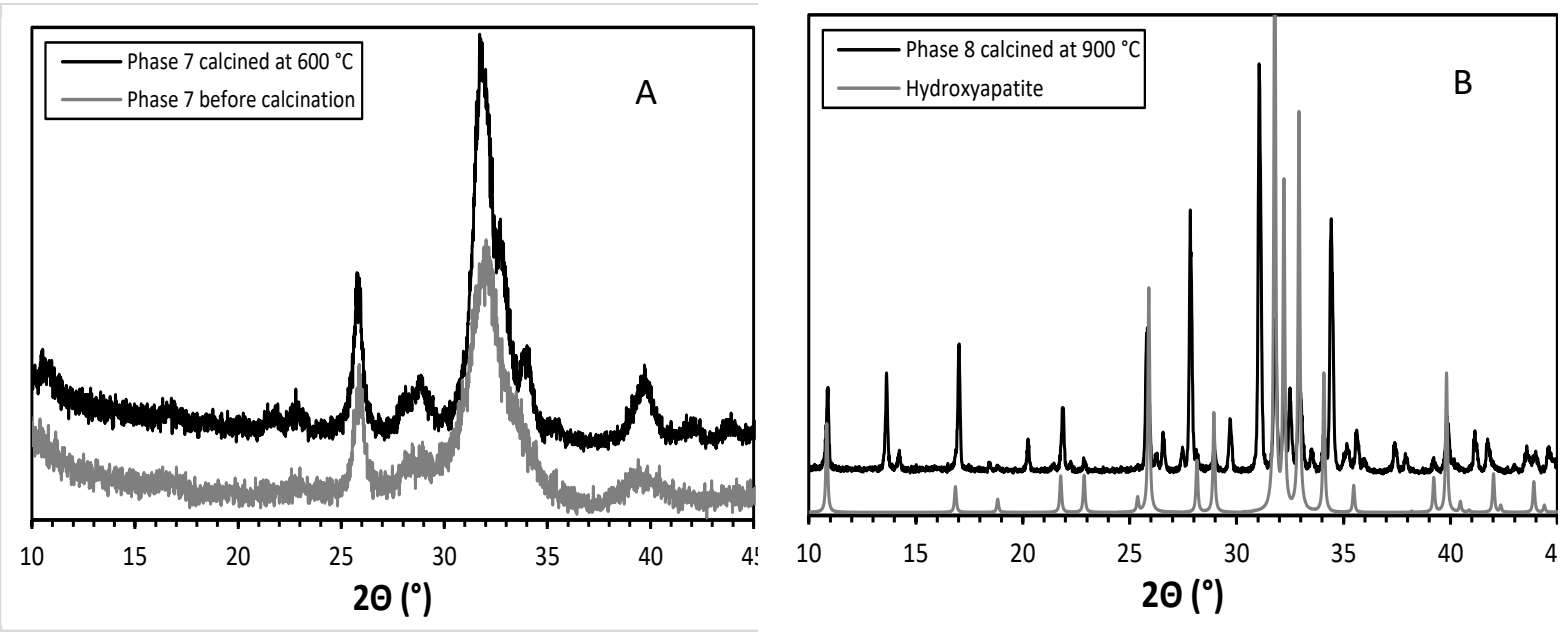

Fig. 8. A: XRD of the precipitate of phase 7 before (grey) and after calcination at $600{ }^{\circ} \mathrm{C}$ (black); B: XRD of the isolate of phase 8 after calcination at $900{ }^{\circ} \mathrm{C}$ (black ) and HAP (grey) as reference.

\section{Economic evaluation}

In the procedure as worked out in this paper the cost for the ultrafiltration becomes supplementary to the nitrification and denitrification which must be done anyway. On an industrial scale a cost of $0.23 € . \mathrm{m}^{3}$ for ultrafiltration can be estimated [27]. With a price of $80 € /$ ton for the $\mathrm{CaCl}_{2}$ solution (33\%; $\left.2.15 \mathrm{~kg} \cdot \mathrm{L}^{-1}\right)$ the cost of $\mathrm{CaCl}_{2}$ to treat $1 \mathrm{~m}^{3}$ of UASB-effluent with about $50 \mathrm{mg}$ phosphate-P per litre and using an added $\mathrm{Ca} / \mathrm{P}$ ratio of 4 , is about 0.17 euro. The total cost to treat $50 \mathrm{~g}$ phosphate- $\mathrm{P}$ from $1 \mathrm{~m}^{3}$ would thus be about $0.40 €$ and the cost to treat $1 \mathrm{~kg}$ of phosphate-P would thus be $8 €$. In current practise ferric trichloride is used to precipitate phosphate together with the sludge at a cost of $5-10 € / \mathrm{kg}$ phosphate-P removed [27]. The cost to remove phosphate as calcium phosphate is thus about the same as in the classic method with ferric trichloride with this difference that the phosphate is also recovered and can be set into the market. If the yield would be $80 \%, 1.3 \mathrm{~mol}$ phosphate-P would be recovered from $1 \mathrm{~m}^{3}$ or the equivalent of about 200 grams calcium phosphate. The cost of recovered calcium phosphate thus is about $2 € / \mathrm{kg}$. A guide value for phosphorous ore is something like $135 €$ /ton. 
The ultrafiltration could not remove all precipitable organic material and makes this way of working expensive. Instead of the ultrafiltration to remove precipitable organic material a selective adsorption might be possible [33]. By doing so the cost to fulfil the legal discharge standards for phosphorus would probably be reduced while still a valuable secondary resource is recovered.

\section{Pilot scale production of phosphoric acid}

\section{Origin of calcium phosphate used}

The product of phase 2 was retained for further investigations. It was dried in the sun and $25 \mathrm{~kg}$ fluffy product was obtained. Drying at $105^{\circ} \mathrm{C}$ and heating at $600{ }^{\circ} \mathrm{C}$ showed that it contained $46 \%$ water and $15 \%$ organic material. The total amount of inorganic material can thus be calculated as $11.5 \mathrm{~kg}$. The $1.83 \mathrm{~m} \% \mathrm{CO}_{2}$ (Table 4) corresponds to $4.16 \mathrm{~m} \% \mathrm{CaCO}_{3}$ contamination and $2.32 \mathrm{~m} \% \mathrm{CaO}$, which is $5.4 \%$ of the total amount of the $\mathrm{CaO}(43.2 \mathrm{~m} \%$; Table 4$) ; 94.6 \%$ of the calcium in the precipitate is thus probably present as calcium phosphate. Table 4 also shows that the contamination of magnesium, as $\mathrm{MgO}$, is $0.472 \mathrm{~m} \%$. This corresponds to $0.28 \mathrm{~m} \%$ as magnesium and $1.03 \mathrm{~m} \%$ as magnesium phosphate.

The product of phase 7 (Fig. 5; Table 4) was also used. Based on the $\mathrm{m} \% \mathrm{CO}_{2}$ which is $3.52 \mathrm{~m} \%$, the $\mathrm{m} \%$ calcium carbonate is $8.0 \mathrm{~m} \%$. Based on the $\mathrm{m} \%$ magnesium $(0.653 \mathrm{~m} \%$ as $\mathrm{MgO}) 1.43 \mathrm{~m} \%$ of the precipitate is magnesium phosphate. Thus, even though batch 7 , which was precipitated from ultra filtered effluent, contained less TOC than batch 2, for the parameter's contamination with calcium carbonate and magnesium phosphate it scored worse.

Calculated relative to the dried precipitates, the combined precipitates contained about $3.8 \mathrm{~m} \% \mathrm{TOC}$, $1.23 \mathrm{~m} \%$ magnesium phosphate (equivalent to $0.56 \mathrm{~m} \% \mathrm{MgO}$ ) and $6.15 \mathrm{~m} \%$ calcium carbonate.

\section{Results of the pilot synthesis of phosphoric acid}

The total yield of phosphoric acid from the mixed precipitates of phase 2 and 7 was about $95 \%$ and the yield on acid consumption was under the limit of $98 \%$. In accordance with the quality of the recovered precipitate, the produced phosphoric acid fulfilled all chemical criteria except for the concentration of chloride and the colour: it contained $3 \mathrm{~m} \%$ chloride and $1600 \mathrm{mg} \cdot \mathrm{kg}^{-1}$ organic carbon, which apparently causes the brown colour; see Figure 9A. The chloride originates from batch 2. The colour did not settle on standing for 6 hours, also not in the presence of a flocculant and thus appears to be soluble organic material; see Figure 9B. This agrees with the idea that most of the organic material that contaminated the precipitate was soluble organic material such as NOM including polyphenols.

The quality of the produced phosphoric acid is not the only criterion to judge the performance of the test. The quality of the produced gypsum is also very important. Figure $10 \mathrm{~A}$ indicates that the test went very well as can be seen from the nice long gypsum crystals that formed. The latter indicates that the concentration of magnesium was not too high as it is known that high concentrations of magnesium inhibit the growth of gypsum crystals [21]. The specification for magnesium $\left(400 \mathrm{mg} \cdot \mathrm{kg}^{-1}\right.$ as $\mathrm{MgO}$ for $15 \mathrm{~m} \% \mathrm{P}_{2} \mathrm{O}_{5}$ ) adopted at the start of the experiment therefore appeared to be too strict. In this kind of precipitates (up to $40 \mathrm{~m} \% \mathrm{P}_{2} \mathrm{O}_{5}$ ), the maximum allowable magnesium concentration probably can be $8 \mathrm{~g}^{\mathrm{kg}} \mathrm{g}^{-1}$ expressed as $\mathrm{MgO}$ (or $0.8 \mathrm{~m} \%$ ) or about $1.8 \mathrm{~m} \%$ as magnesium phosphate. Previous work showed that phosphate recovery as its calcium salt after a nitrification resulted in less than $2 \mathrm{~m} \%$ contamination with magnesium phosphate whereas the same process after an additional denitrification resulted in about $6 \mathrm{~m} \%$ contamination with magnesium phosphate [20]. 


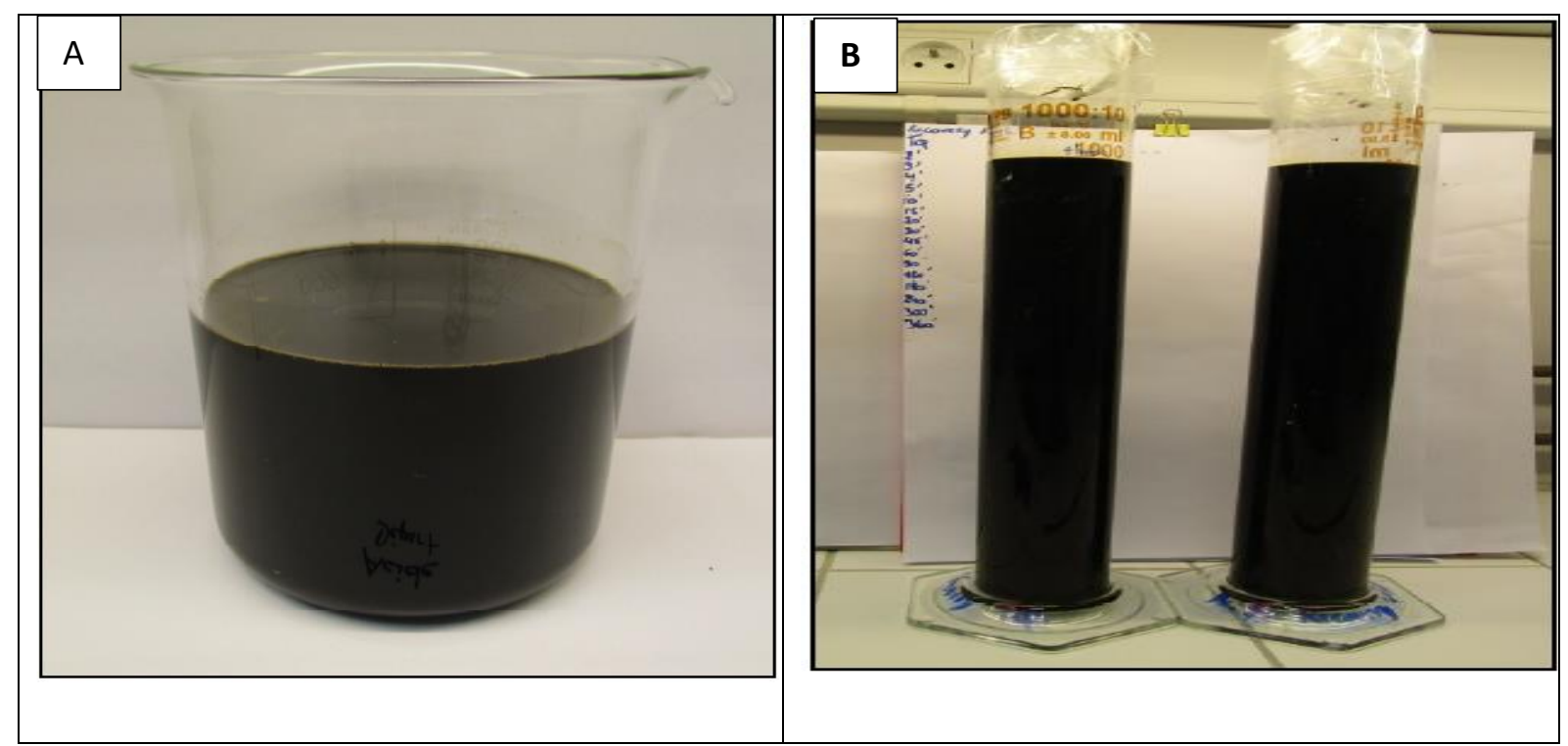

Figure 9 : A: Beaker with a sample of the produced phosphoric acid. B: The colour did not precipitate also not in the presence of a coagulant (right hand place).

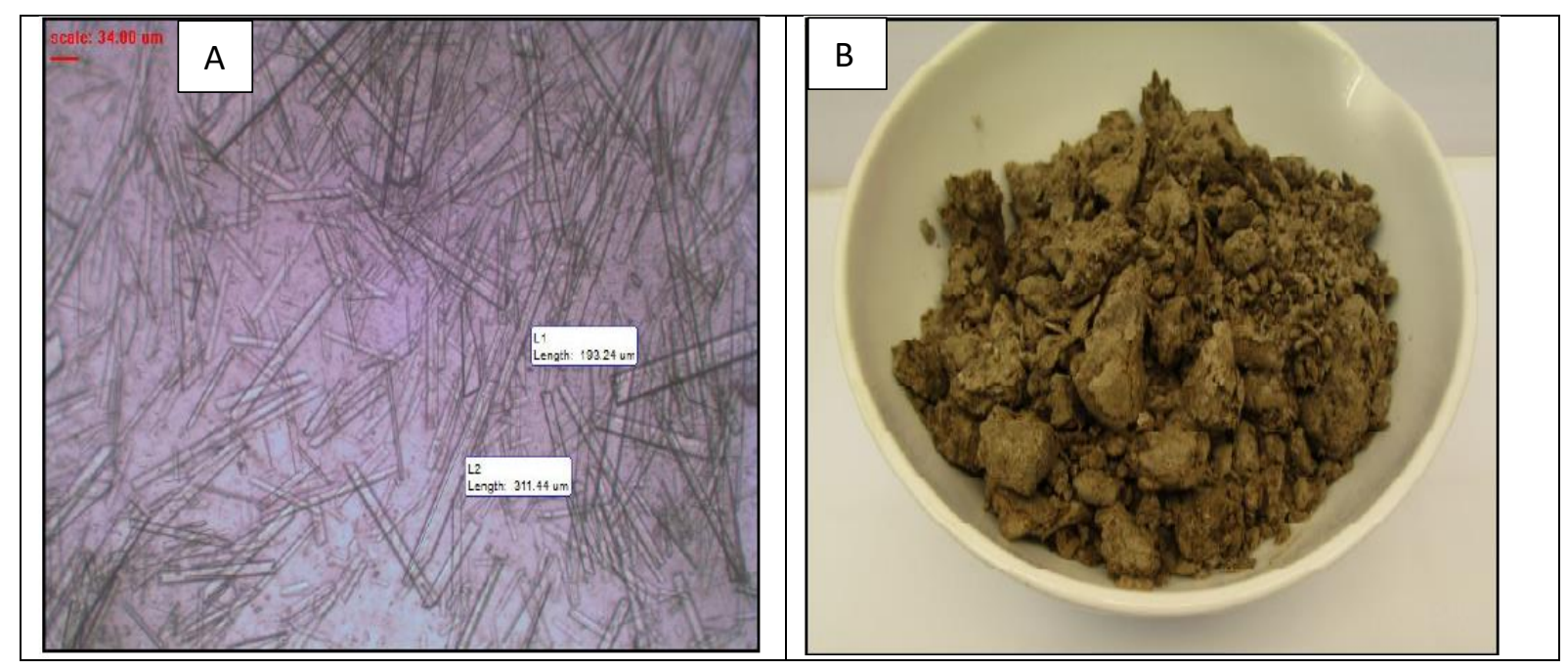

Figure 10: Quality of the produced gypsum; A: needles of calcium sulphate as observed with a light microscope; needles of 193 and $311 \mu \mathrm{m}$ are indicated; B: Aspect of the gypsum produced.

The precipitation of phosphate as calcium phosphate at neutral $\mathrm{pH}$ after nitrification to consume the DIC and release the necessary calcium ions is thus a good approach to recover phosphorus with an acceptable contamination with magnesium.

Figure $10 \mathrm{~B}$ shows that most of the organic material accumulates in the gypsum, making the latter unusable for its classic use. This pilot scale phosphoric acid production thus demonstrates that not magnesium but instead the organic contamination is the problem with this kind of precipitates. This contaminating organic material causes the discoloration of both the recovered phosphoric acid and gypsum.

It is obvious that the encountered problems with organic material can be circumvented by not using the precipitated calcium phosphate as such but by mixing it with phosphorous ore. The recovered calcium phosphate can e.g. be mixed in a such a proportion with the ore that the finally attained 
concentration of any contaminant is lower than its stated maximum value. E.g., Nippon Phosphoric Acid Co uses sewage sludge ash (SSA) for the industrial manufacturing of phosphoric acid. SSA is blended in roller -milled phosphate rock at a final concentration of only 2-3 \% just to guarantee the quality of the produced phosphoric acid and the by-product gypsum [34].

The pilot scale preparation was performed on a mixture of the batches 2 and 7 which were both colored as was batch 8 ; see Fig. $6 \mathrm{~A}$. Calcination at $600^{\circ} \mathrm{C}$ of batch 8 removed the contaminating organic material and the brown color and complete discoloration was obtained after calcination at $900{ }^{\circ} \mathrm{C}$; see Figures $6 \mathrm{~B}$ and $\mathrm{C}$. It is obvious that a much better result in terms of purity and color for both phosphoric acid and gypsum would have been obtained if the mixed precipitate first was calcined before subjecting it to the pilot test for phosphoric acid production. It is of course highly questionable whether such a calcination can be an economically viable pretreatment in the wet process for phosphoric acid production.

Other uses of this type of phosphate containing precipitates are also possible. As precipitates from agro-industry they are pathogen free since the treated UASB effluent is not contaminated with human or animal excrements as they just consist of used wash water and blanching water of vegetable or potato processing. This calcium phosphate salts are therefore probably suited as biophosphate source for animal food. Their low contamination with heavy metals such as $\mathrm{Cd}$ and with uranium (Table 4) makes that this kind of precipitates furthermore may be of interest in the electro or carbothermal reduction processes to white phosphorus. According to Ohtake [35] it is necessary to redefine the $P$ value chain especially in view of the availability of white or elemental phosphorus. The latter is a very highly critical raw material since mined phosphate rock is increasingly contaminated with heavy metals and radioactive elements; it was added to the European list of critical raw materials [36]. Elemental phosphorus is essential for manufacturing high value-added products such as semiconductors, lithium batteries, liquid crystal panels, medicines and fireretardant plastics.

\section{Conclusions}

In the frame of the sustainable use of phosphorus, a pilot scale experiment ran for more than one year on the effluent of an upstream anaerobic sludge blanket reactor (UASB) of a potato processor to recover phosphate as calcium phosphate. Aeration and nitrification of the UASB effluent resulted in complete removal of ammonium, while correspondingly a double equimolecular amount of DIC was consumed. The DIC decreased to a rather constant value of $10 \mathrm{mmol}^{-\mathrm{L}^{-1}}$ and indicated that part of DIC was also simply blown out during the last phases of the experiment. In this way calcium ions become available for calcium phosphate formation and precipitation.

At a pH of about 7.5, a phosphate-P concentration of 1.5 to $2 \mathrm{mmol} . \mathrm{L}^{-1}$ corresponding to an initial molar $\mathrm{Ca} / \mathrm{P}$ ratio of 1.0 to 0.7 and adding calcium ions from calcium chloride in ratio of about 4 or 8-9 relative to the concentration of endogenous phosphate, resulted in $80 \%$ respectively $90 \%$ decrease of the phosphate-P concentration. The phosphate-P was effectively recovered in the precipitate as calcium phosphate. The precipitate was moderately contaminated with calcium carbonate $(4-8 \mathrm{~m} \%)$ and magnesium phosphate (about $3 \mathrm{~m} \%$ ).

Without ultrafiltration the precipitates contained considerable amounts of organic material; when expressed as organic carbon, more than $6 \mathrm{~m} \%$. These precipitates were also contaminated with potassium (in a molar K/P ratio of 0.06 to 0.16 ). Ultrafiltration reduced the organic material by more than $50 \%$, but also indicated that dissolved organic material is entrapped in the precipitates. In the 
best conditions, total carbon was reduced to $2 \mathrm{~m} \%$ including $1.67 \mathrm{~m} \% \mathrm{TOC}$, which however still corresponds to $7 \mathrm{~m} \%$ organic material.

The phosphorous content of the precipitates was expressed as $\mathrm{P}_{2} \mathrm{O}_{5}, 35$ to $40 \mathrm{~m} \%$. After extensive washing of the precipitates, chloride was present in an amount that was just acceptable, while both organic carbon and magnesium exceeded the allowed content by a factor four to five.

The way of feeding (continuous vs discontinuous) or mixing (continuous vs discontinuous; mechanical stirring or by a submersed pump) the reactor had apparently no influence on the recovery of phosphate-P. Aeration of the reactor stimulated the precipitation of calcium phosphate as hydroxyapatite.

In the reactor for phosphate recovery a brown colour developed that may be linked to the presence of polyphenols in potato tubers. Colour and organic material were removed from the precipitations by calcination at $600{ }^{\circ} \mathrm{C}$ and made the precipitates to fulfil the criterion for organic contamination asked by phosphorous industry. Calcination at $900^{\circ} \mathrm{C}$ removed inorganic contamination. Both calcination at $600{ }^{\circ} \mathrm{C}$ and $900^{\circ} \mathrm{C}$ ameliorated the crystallinity of the precipitates.

$30 \mathrm{~kg}$ of mixed non-calcinated precipitates was subjected to a pilot test for phosphoric acid production. The produced acid and gypsum were coloured, a flaw that more than likely finds its cause in the organic matter present in the precipitates. The contaminating magnesium corresponding to $1.2 \mathrm{~m} \%$ magnesium phosphate did not hinder the crystallization of gypsum nor the formation of phosphoric acid. The produced phosphoric fulfilled all chemical criteria except those to which the precipitate as such also failed.

The two basic technologies used in this experiment, nitrification and ultrafiltration, made the recovery of a precipitate possible with a high $\mathrm{P}_{2} \mathrm{O}_{5}$ content (up to $40 \%$ ), but could not completely overcome some basic problems of phosphate recovery: the recovered precipitates were contaminated with magnesium and organic material. The amount of magnesium in the precipitate finally appeared to be low enough to avoid problems during phosphoric acid production, but the organic material caused discoloration of both the recovered phosphoric acid and gypsum. It rests of course possible to mix the recovered calcium phosphate with phosphorous ore in such relative amounts that the organic contamination of the mix does not exceed its allowable maximum level.

In the frame of redefining the global phosphorous cycle one must also consider other applications of recovered phosphate from wastewater of agro-industry.

\section{Acknowledgements}

The authors gratefully acknowledge financial support through the TETRA project "Phosphate Recovery 2.0" (HBC.2017.0029) by the Flanders Agency for Innovation \& Entrepreneurship (VLAIO). Cédric Van Goethem is grateful to Research Foundation Flanders (FWO) for a junior postdoctoral fellowship (12ZQ420N). VLAKWA-VITO (Flemish Knowledge Centrum Water - Flemish Institute for Technological research), Belgapom (Professional association of the Belgian Potato Trade and Processing companies) and VeGeBe (Federation of the Belgian Vegetable Processors and Traders in Industrial Vegetables) are acknowledged for their help and encouragement during the project. Agristo NV (Wielsbeke, Belgium) is acknowledged for its hospitality, for supplying UASB effluent and practical help. 


\section{References}

[1] Desmidt E., Ghyselbrecht K., Zhang Y., Pinoy L., Van der Bruggen B., Verstraete W., Rabaey K. \& Meesschaert B. (2015). Global phosphorus scarcity and full-scale P-recovery techniques: a review, Critical Reviews in Environmental Science and Technology, 45:336-384.

[2] Woods N., Sock S., \& Daigger G. (1999). Phosphorus recovery technology modelling and feasibility evaluation for municipal wastewater treatment plants. Environmental Technology, 20: 663 -679.

[3] https://phosphorusplatform.eu/scope-in-print/news/359-phosphate-rock-in-eu-critical-rawmaterials-list

[4] Verordnung zur Neuordnung der Klärschlamverwertung (27-09-2017) Bundesgesetzblatt, Jahrgang 2017 Teil I, 65, Bonn, Germany.

[5] Foy R.H. \& Withers P. J. A. (1998). Phosphate removal and recovery from wastewater, J. Phosphate and Potassium, 213

[6] Moerman W., Carballa M., Vandekerckhove A., Derycke D. \& Verstraete W. (2009). Phosphate removal in agro-industry: Pilot- and full-scale operational considerations of struvite crystallization, Water Research, 43: 1887 - 1892.

[7] Vanotti, M. B., Szogi, A.A. \& Hunt P.G. (2003). Extraction of soluble phosphorus from swine wastewater, Transactions of the American Society of Agricultural Engineers, 46: 1665 - 1674.

[8] Vanotti M. \& Szogi A. (2009). Technology for the recovery of phosphorus from animal wastewater trough calcium phosphate precipitation, International conference on Nutrient Recovery from Wastewater Streams, Ashley K., Mavinic D. \& Koch F. (Ed.), IWA publishing, London.

[9] Driver J., Lijmbach D. \& Steen I. (1999) Why recover phosphorus for recycling and how? Environmental. Technology, 20: $651-662$.

[10] Morse G.K., Brett S.W., Guy, J.A. \& Lester J.N. (1998. Review: Phosphorus removal and recovery technologies, The science of the Total Environment, 212:69-81.

[11] Eggers E., Dirkzwager A.H. \& van der Koning, H. (1991). Full-scale experiences with phosphate crystallisation in a crystalactor, Water Science and Technology, 24: $333-334$.

[12] Chen X., Kong H., Wu D, Wang X. \& Lin Y. (2009). Phosphate removal and recovery through crystallisation of hydroxyapatite using xonotlite, Journal of Environmental sciences, 21: $575-580$.

[13] Li H., Ge W., Zhang J., Kasomo R. M., Leng J., Weng X., Chen Q., Gao Q., Song S., Xiao L. \& Tian C. (2020) Control foaming performance of phosphate rocks used for wet-process of phosphoric acid by phosphoric acid. Hydrometallurgy, doi.org/10.1016/hydromet.2020.105364

[14] Song Y., Hahn H.H. \& Hoffmann E. (2002). The effect of carbonate on the precipitation of calcium phosphate, Environmental technology, 23: 207-215.

[15] Monballiu A., Desmidt E., Ghyselbrecht K. \& Meesschaert B. (2018). The inhibitory effect of inorganic carbon on phosphate recovery from upflow anaerobic sludge blanket reactor (UASB) effluent as calcium phosphate, Water Science and Technology, 78: 2608-2615.

[16] Monballiu A., Desmidt E., Ghyselbrecht K. \& Meesschaert B. (2018). Phosphate recovery as hydroxyapatite from nitrified UASB effluent at neutral pH in a CSTR. Journal of Environmental Chemical Engineering, 6, 4413-4422. 
[17 ] Toyama T. (2019) Phosphorus extraction from sewage sludge ash by the $\mathrm{CO}_{2}$ blowing method. Chapter 13 in: Phosphorus recovery and recycling (Ed: Ohtake $\mathrm{H}$ and Tsuneda S). Springer Singapore ISBN 978-981-10-8030-2

[18 ] Schnee R. \& Opitz E. (2019) Phosphorus Recovery from wet sewage sludge using $\mathrm{CO}_{2}$. Chapter 20 in: Phosphorus recovery and recycling (Ed: Ohtake H and Tsuneda S). Springer Singapore ISBN 978-981-10-8030-2

[19] Monballiu A., Ghyselbrecht K., Crabeels X. \& Meesschaert B. (2018). Calcium phosphate precipitation in nitrified wastewater from the potato processing industry. Environmental Technology, 40 (17): $2250-2266$

[20] Monballiu A., Ghyselbrecht K., Pinoy L. \& Meesschaert B. (2020). Phosphorous Recovery as Calcium Phosphate from UASB Effluent after nitrification with or without subsequent denitrification. Journal of Environmental Chemical Engineering, doi.org/10.1016/j.jece2020.104119.

[21] Boukhsib A., Khamar L., Saddik Kadiri M. \& Omari L. (2019) Effects of magnesium content on the rheological behaviour of phosphoric acid and on the performance of his industrial manufacturing by the dihydrate wet processes. International Journal of Engineering Sciences \& Research Technology, 8 (7), 1 - 14.

[22] Lei Y., Song B., van der Weijden R.D., Saakes M. \& Buisman C.J.N (2017). Electrochemical induced calcium phosphate precipitation: importance of local pH. Environmental Science \& Technology, 51: 11156 - 11164.

[23] Lei Y., Remmers J. C., Saakes M., van der Weijden R.D. \& Buisman C.J.N. (2018). Is there a precipitation sequence in municipal wastewater induced electrolysis? Environmental Science \& Technology, 52: 8399 - 8407.

[24] Vasenko L. \& Qu H. (2017) Effect of $\mathrm{NH}_{4}-\mathrm{N} / \mathrm{P}$ and $\mathrm{Ca} / \mathrm{P}$ molar ratios on the reactive crystallization of calcium phosphates for phosphorus recovery from wastewater. Journal of Crystal Growth, 459: 61 $-66$.

[25] Alvaro M., Esplá M., Llinares J., Matiñez \& Soto J. (1993). A small-scale, easy to run wastetreatment plant. Journal of Chemical Education, 70: A129 - A132.

[26] Monballiu A., Ghyselbrecht K., Pinoy L. \& [Meesschaert B. (2020). Phosphorus Reclamation by End-of-pipe recovery as calcium phosphate from effluent of wastewater treatment plants of agroindustry, Journal of Environmental Chemical Engineering, doi.org/10.1016/j.jece2020.104280.

[27] Personal communication from Belgapom (Professional association of the Belgian Potato Trade and Processing companies) and VeGeBe (Federation of the Belgian Vegetable Processors and Traders in Industrial Vegetables)

[28] Lei Y., Song B., Saakes M., van der Weijden R.D. \& Buisman C.J.N. (2018). Interaction of calcium, phosphorus and natural organic matter in electrochemical recovery of phosphate; Water Research 142: 10 - 17.

[29] Akyol H., Riciputi Y., Capanoglu E., Caboni M. F. \& Verando V; (2016). Phenolic compounds in the potato and its by-products: an overview, International Journal of Molecular Sciences, 17(6): 835-853.

[30] van Santen R.A. (1984) The Ostwald step rule. Journal of Physiological Chemistry 88: 5768-5769. 
[31] Karampas I.A. \& Kontoyannis C.G. (2013).Characterisation of calcium phosphate mixtures. Vibrational Spectroscopy, 64:126-133.

[32] Landi E., Tampieri A., Celotti G. \& Spiro S.(2000). Densification behaviour and mechanisms of synthetic hydroxyapatites. Journal European Ceramic Society, 20: 2377-2387.

[33] Bhatnager A, \& Sillanpää M. (2017) Removal of natural organic matter (NOM) and its constituents from water by adsosrption - A review. Chemosphere, 166:497 - 51.

[34] Mochiyama T. (2019) Industrial-scale manufacturing of phosphoric acid using sewage sludge ash. Chapter 7 in: Phosphorus recovery and recycling (Ed: Ohtake $\mathrm{H}$ and Tsuneda S). Springer Singapore ISBN 978-981-10-8030-2

[35] Ohtake H. (2018) Recovery, reuse of phosphorus from wastewater. The Japan Times - IWA World Water Congress \& Exhibition, 122 (42584): B3

[36] https://phosphorusplatform.eu/scope-in-print/news/1534-white-phosphorus-added-eu-crm 